\section{Vascular compression syndromes: a pictorial review}

\author{
Renato Farina, Pietro Valerio Foti, Isabella Pennisi, Tiziana Vasile, Mariangela Clemenza, \\ Giuliana La Rosa, Luca Crimi, Marco Catalano, Francesco Vacirca, Antonio Basile \\ Department of Surgical and Medical Sciences, Advanced Technologies GF Ingrassia, \\ University of Catania, Catania, Italy
}

Vascular compression syndromes include a group of rare vascular changes due to extrinsic compression of veins or arteries by surrounding structures. These pathologies are often underestimated due to their rarity, clinicians' poor level of knowledge, and the non-specificity of their symptoms. The best known are Eagle syndrome, thoracic outlet syndrome, nutcracker syndrome, May-Thurner syndrome, Dunbar syndrome, and popliteal entrapment syndrome. This work summarizes the main ultrasonographic characteristics, symptoms, and treatments of choice for these syndromes. Knowledge of these conditions' characteristic signs is essential for the differential diagnosis. Failure to diagnose these rare diseases can expose patients to serious complications and risks to their health.

Keywords: May-Thurner syndrome; Dunbar syndrome; Nutcracker syndrome; Eagle syndrome;

Thoracic outlet syndrome; Popliteal entrapment syndrome

Key points: Vascular compression syndromes comprise a group of rare vascular changes. Knowledge of the main ultrasound characteristics of these pathologies is essential for the differential diagnosis.

\section{Introduction}

Vascular compression syndromes are rare and little-known pathologies that represent a very important subset of vascular alterations. The recognition of vascular compression syndromes is difficult when they are still asymptomatic due to the non-specificity of their symptoms, and they are often randomly identified in routine examinations; only when the compression is severe and becomes symptomatic does it become possible for instrumental examinations to highlight characteristic signs that allow a differential diagnosis. Knowledge of these signs and typical symptoms is essential for their recognition. When patients have minimal asymptomatic vascular compressions, in most cases they are ignored, exposing them to serious risks for their health related to the worsening of compressions and complications (thrombosis, pulmonary embolism, cerebral embolism, etc.). Recognizing vascular compressions promptly and evaluating their severity is essential for proper therapeutic planning. Doppler ultrasonography (DU), which is the first-line examination for the diagnosis of vascular compression, enables clinicians to highlight the morphological changes and, above all, to measure the degree of vascular stenosis. After identifying the site of compression and

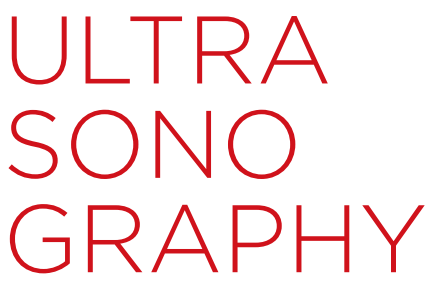

\section{REVIEW ARTICLE}

https://doi.org/10.14366/usg.21233 pISSN: 2288-5919 • elSSN: 2288-5943 Ultrasonography 2022;41:444-461

Received: November 6, 2021 Revised: February 23, 2022 Accepted: February 23, 2022

Correspondence to: Renato Farina, Department of Surgical and Medical Sciences, Advanced Technologies GF Ingrassia, University of Catania, Via Santa Sofia, 78-95123 Catania, Italy

Tel. $+39-3248764148$

Fax.+39-095491961

E-mail: radfaro@hotmail.com

This is an Open Access article distributed under the terms of the Creative Commons Attribution NonCommercial License (http://creativecommons.org/ licenses/by-nc/4.0/) which permits unrestricted noncommercial use, distribution, and reproduction in any medium, provided the original work is properly cited.

Copyright (C) 2022 Korean Society of Ultrasound in Medicine (KSUM)

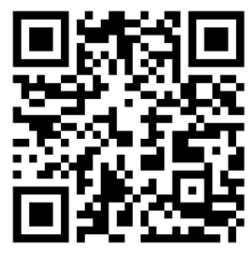

How to cite this article:

Farina R, Foti PV, Pennisi I, Vasile T, Clemenza $M$, Rosa GL, et al. Vascular compression syndromes: a pictorial review. Ultrasonography. 2022 Jul;41(3):444-461. 
indirect signs, such as dilatation of the prestenotic and poststenotic tract, the increase in flow in the stenotic tract, and the peak systolic velocity (PSV) reduction in the prestenotic tract, it is necessary to quantify the degree of stenosis, which is achieved with the flow ratio (FR). The venous FR is obtained from the PSV ratio of the poststenotic tract and prestenotic tract (poststenotic PSV/prestenotic PSV), while the arterial FR is obtained from the ratio between the PSV of the poststenotic tract and the aortic PSV (poststenotic PSV/aortic PSV). A venous FR of 2.5 corresponds to stenosis of $50 \%$ [1], whereas an FR of 3:1 corresponds to stenosis of $70 \%$ [2]. DU currently can be performed with low-, medium-, or highend ultrasound devices, as well as portable equipment equipped with color and duplex DU. Ultrasonography makes it possible to localize and estimate stenosis severity in vascular compression syndromes. In some cases, ultrasonography does not suffice, and to reach a conclusive diagnosis, a second-line method is necessary to identify compressions of nervous structures, as in thoracic outlet syndrome (TOS), Dunbar syndrome (DS), Eagle syndrome (ES), and popliteal entrapment syndrome (PES); to exclude other causes of compression (abdominal masses, aneurysms, pseudoaneurysms, surgical sequelae); or to highlight complications such as pulmonary embolism, cerebral embolism, ictus, or cerebral venous sinus thrombosis. Intravascular ultrasound imaging (IVUS) [3], which has recently become the reference method for arterial and venous pathologies, allows direct evaluation of endoluminal content. This method is particularly useful for the diagnosis and management of numerous vascular diseases, including aneurysms, dissections, thrombosis, and stenosis, and it has also been used in some vascular compression syndromes. In this work we retrospectively examined 132 cases that passed through our imaging department from 2013 to date, including 14 cases of ES, 30 cases of nutcracker syndrome (NCS), 30 cases of May-Thurner syndrome (MTS), 12 cases of DS, 12 cases of TOS, and 34 cases of PES. The main features, symptoms, instrumental investigations, and current therapeutic guidelines were summarized for each syndrome. The data that emerged were compared with data from the literature. Written informed consent was obtained from the patients for publication of this review and any accompanying images and clips.

\section{Eagle Syndrome}

\section{Introduction}

ES is caused by a very elongated and anteromedially inclined styloid process (SP) and/or by a calcific stylohyoid ligament, which compresses contiguous vascular and nerve structures (Fig. 1A) [4]. ES has a higher incidence in women and can be unilateral or bilateral. This rare syndrome is not well known, and vascular compressions are often discovered during routine radiological or ultrasound examinations. According to the authors, the cause of SP elongation or ligament ossification may be due to abnormalities in bone development and/or homeostasis [5]. In the literature, a length of the SP greater than $2.5 \mathrm{~cm}$ [6] or greater than $4.0 \mathrm{~cm}$ [7] is considered anomalous; moreover, a distance of $3.9 \mathrm{~mm}$ between the SP and first cervical vertebra is considered anomalous. ES can also be caused by an SP of normal length but with abnormal tip angulation [8].

\section{Clinical Presentation}

Based on the structures that are compressed by the SP, ES has been classified into three subtypes.

(1) Classical syndrome with compression of the glossopharyngeal nerves or $\mathrm{V}-\mathrm{VII}$ and $\mathrm{X}$, causing symptoms such as tinnitus, ear pain, dysphagia, foreign body sensation, altered voice, and a hypersalivation sensation [9].

(2) Stylus carotid syndrome with impingement of the internal carotid arteries, resulting in transient ischemic attacks and strokes.

(3) Stylo-jugular venous compression syndrome, which causes congestion of venous flow in the internal jugular vein (Fig. 1A, Video clip 1) with a risk of thrombosis, intracranial hypertension, cerebral sigmoid sinus thrombosis, and subarachnoid hemorrhage.

\section{Instrumental Diagnosis}

The differential diagnosis is difficult due to the non-specificity of symptoms and must include all pathologies that cause the same symptoms. Conventional radiography (CR) alone is insufficient for the diagnosis, as it can show an abnormal length of the SP but not vascular or nerve compression; therefore, it requires further instrumental investigations. Computed tomography (CT) shows an elongated SP (Fig. 1B, C) and vascular stenosis, highlighting vascular complications (e.g., cerebral venous sinus thrombosis, compensatory circulation, and stroke). DU can localize vascular compression and flow congestion in the jugular vein or carotid artery but, unlike CT and magnetic resonance imaging (MRI), can provide an estimate of the degree of stenosis by calculating the FR (Fig. 1D, E). Knowledge of the stricture extension is essential for treatment planning. MRI (Fig. 1F) can highlight vascular stenosis, but especially nerve stenoses [10].

\section{Treatment}

Therapy varies according to symptoms, the severity of vascular compression, and the presence of thrombosis. In less severe cases, treatment can be conservative, such as steroids, anticoagulants, or anesthetic drugs [11]; while in cases of severe stenosis (>70\%), endovascular stenting [12], SP surgical removal [13], or calcific 


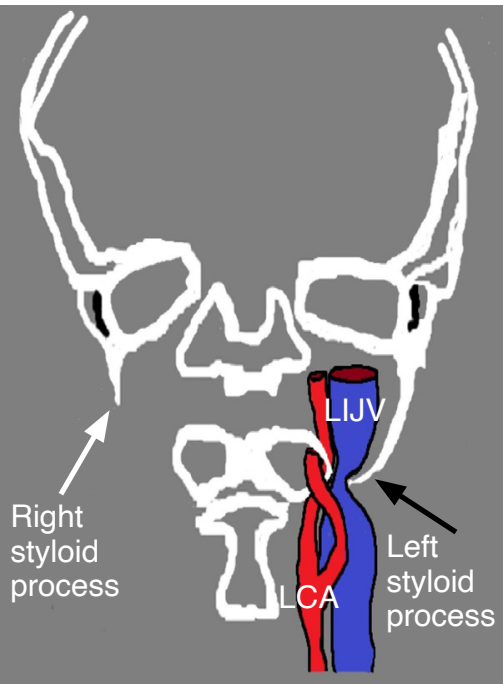

A

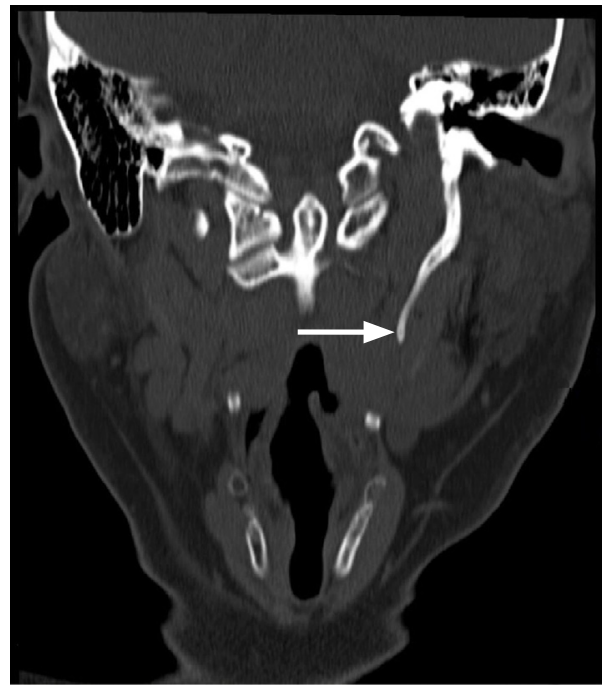

B

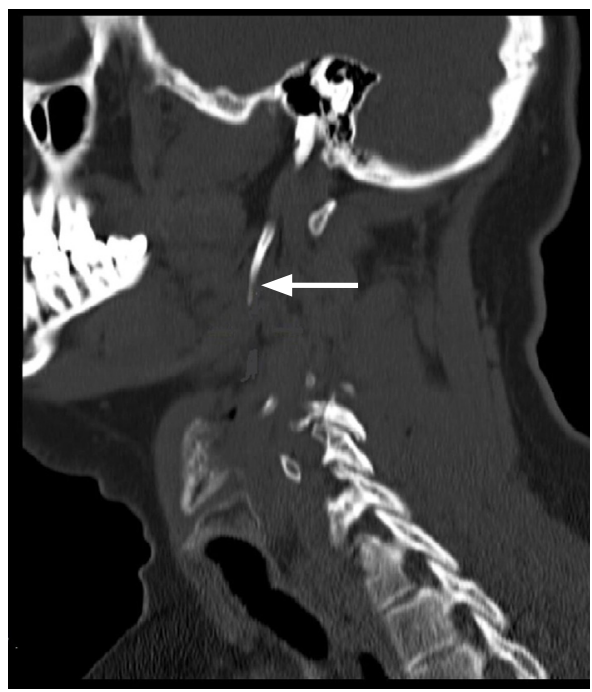

C

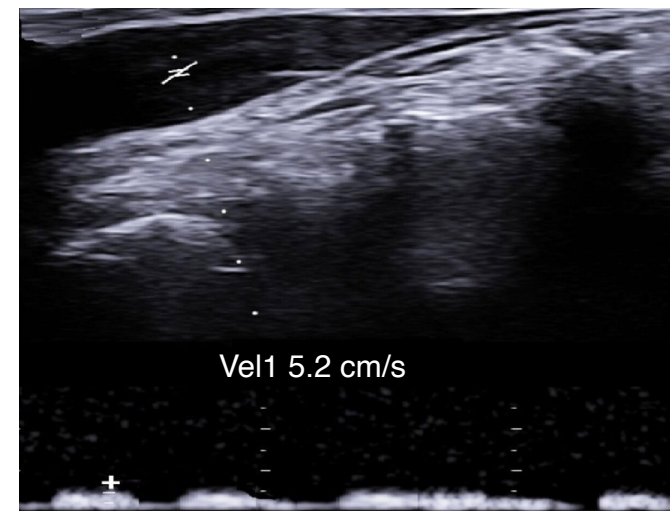

D

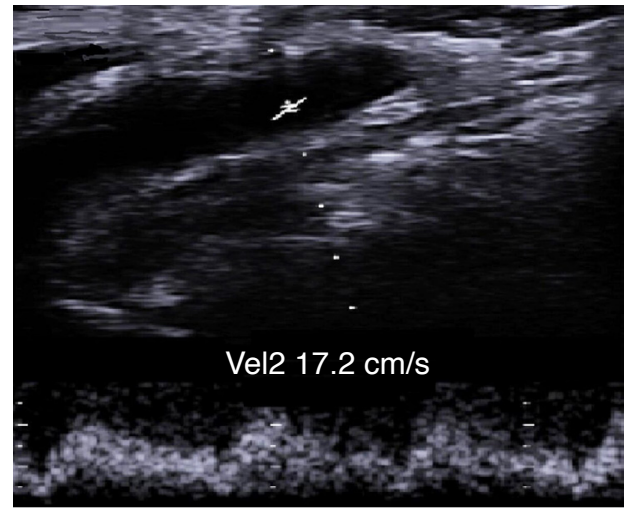

$\mathrm{E}$

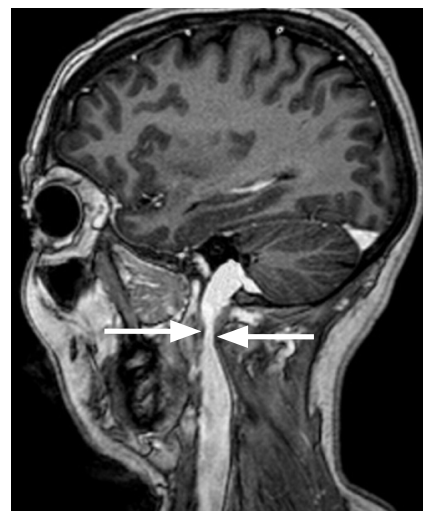

F

Fig. 1. Summary schematic graphical presentation and some representative computed tomography (CT), Doppler ultrasonography and magnetic resonance images of Eagle syndrome.

A. Diagram in the coronal plane summarizes the anatomical relationships between the bone and vascular structures involved in Eagle syndrome. An elongated and anteriorly inclined styloid process (SP) (black arrow) compresses the left internal jugular vein (LIJV) against the transverse process of C1. LCA, left common carotid artery; white arrow, right SP. B. The CT scan in the coronal plane view shows a very elongated $(6.5 \mathrm{~cm}$ ) and medially angled left SP (arrow). C. The CT scan in the sagittal-plane view shows anterior angulation of the SP (arrow). To calculate the flow ratio, it is necessary to use duplex Doppler ultrasonography to measure the peak systolic velocity of the prestenotic (D) and poststenotic (E) tracts of the internal jugular vein (IJV). F. In this magnetic resonance imaging sagittal-plane view, it is possible to highlight IJV stenosis (arrows).

stylohyoid ligament surgical removal [14] may be indicated. Furthermore, long-term prophylaxis with anticoagulant therapy with a daily dose of low-molecular-weight subcutaneous injection of heparin-with agents including Bemiparin (Ivor), enoxaparin (Clexane, Clexane T), nadroparin (Fraxodi, Fraxiparina, Seledie, Seleparina), parnaparin (Fluxum) is recommended in asymptomatic patients with $\geq 50 \%$ carotid or internal jugular vein stenosis and follow-up with DU at 6 or 12 months.

\section{Thoracic Outlet Syndrome}

\section{Introduction}

TOS can be caused generally by scalene muscle hypertrophy or a cervical rib, which can compress the brachial plexus (neurological form) [15], subclavian artery [16], and/or subclavian vein [17] (vascular form). Brachial plexus and subclavian artery compression is usually caused by a cervical rib, while hypertrophy of the anterior scalene muscle is the most common cause of subclavian vein stenosis. Scalene muscle hypertrophy is common in athletes who stress the 
shoulder muscles [18]. Cervical ribs and scalene muscle hypertrophy can be unilateral or bilateral; they are often asymptomatic and have a higher incidence in women. Subclavian artery and brachial plexus compressions always occur in the space called the interscalenic triangle, which is delimited anteriorly by the anterior scalene muscle, posteriorly by the medial scalene, and inferiorly by the medial side of first rib; in this space, compression is caused by a cervical rib (Fig. 2A). Subclavian vein compression occurs in the costo-clavicular space, which is an anatomical space delimited by the clavicle at the top, by anterior scalene muscle laterally and by first rib at the bottom (Fig. 2B); in this space, anterior scalene muscle hypertrophy can cause subclavian vein compression. The subclavian vessels and the brachial plexus can also be compressed in the subcoracoid or minor pectoral space, in the angle between the pectoralis minor tendon and where it attaches to the coracoid process; if symptomatic, this compression is known as pectoralis minor syndrome and is part of the TOS. Neurological TOS accounts for $95 \%$ of cases, arterial TOS for $1 \%$, and venous TOS for $2 \%-3 \%$.

\section{Clinical Implications}

On clinical examination, subclavian artery compression is accentuated with raised arms, which also cause the reduction or disappearance of the radial pulse (the Adson test) [19]; the arterial flow deficit causes hypoperfusion, hypothermia, and upper limb cyanosis. Subclavian vein compression instead causes the signs of venous congestion with cyanosis, pain, and upper limb swelling. The neurological form generally manifests with tingling in the upper limb, paresthesia, and functional impotence.

\section{Instrumental Diagnosis}

The diagnosis is based on neurological, clinical, and instrumental examinations. The instrumental examinations involve CR (Fig. 2C, D), DU, CT, MRI, conventional arteriography, and IVUS to highlight the cervical ribs, vascular and nerve compressions, and the degree of stenosis. The FR measurement (Fig. 2E-H) is necessary and provides valuable information for therapeutic planning. MRI is required for the study of brachial plexus, scalene, and pectoralis minor muscles [20]. The CT and DU examinations must be performed with the arms raised and lowered (Fig. 2I-K) because compression often does not occur with lowered arms. According to studies in the literature, IVUS detected higher levels of stenosis than venography, highlighting venous lesions not diagnosed with other imaging methods [21].

\section{Treatment}

In patients with mild symptoms, TOS treatment can be conservative, involving physiotherapy, massage, and kinesitherapy [22]. When compressions are significant $(>70 \%)$, surgery is the treatment of choice [23]. The surgical treatment is scalenectomy, usually combined with first rib or cervical resection, and may require scar tissue lysis around neurovascular structures aimed at decompression of the involved structures. In arterial TOS, the stenotic tract is often the site of changes due to chronic compression of the endothelium and degeneration that often follows. These changes, in combination with slow flow, can cause thrombosis or poststenotic aneurysm or pseudoaneurysm, which must be carefully evaluated regardless of the symptoms; this is an important imaging finding that must be considered during treatment/reconstruction to remove not only a section of stenosis, but also of the aneurysm. If not diagnosed in time, these alterations can cause thrombosis with extensive embolization. According to some authors, endovascular stenting in combination with surgery could be a valid alternative to the traditional surgical approach in cases of cervical rib [24], while according to others, endovascular stenting is generally not a primary treatment for TOS and should be discouraged in the absence of previous open decompression.

\section{Nutcracker Syndrome}

\section{Introduction}

NCS is caused by left renal vein (LRV) compression by the superior mesenteric artery (SMA) against the aorta (anterior nutcracker syndrome, ANCS) [25] or by the left retroaortic renal vein in the passage between the aorta and spine (pseudo-nutcracker syndrome, PNCS) (Fig. 3A-C) [26]. It can be acquired or congenital [27]. The acquired form of ANCS is common in patients with anorexia who, due to significant weight loss, undergo a noticeable reduction in perivascular adipose tissue layer, causing aorto-mesenteric angle reduction (Video clip 2). In healthy patients, the angle between the SMA and aorta is greater than $22^{\circ}$ and the distance between the two vessels is greater than $8 \mathrm{~mm}$. In PNCS, there is still no cutoff value for the minimum distance between the aorta and spine, beyond which the syndrome occurs. PNCS is caused in most cases by aortic and/or vertebral pathologies (e.g., aneurysms or lumbar osteophytosis). In rare cases, aorto-mesenteric angle reduction causes duodenum compression; these cases are known as Wilkie syndrome (WS) [28]. There is also an anatomical variant known as renal collar or a circum-aortic venous ring, characterized by presence of two LRVs that pass anteriorly and posteriorly to the aorta. In these patients, the simultaneous compression of two veins is referred to as combined nutcracker syndrome. The combination of ANCS and WS is very rare [29].

\section{Clinical Presentation}

The symptoms of ANCS and PNCS are related to the severity of 


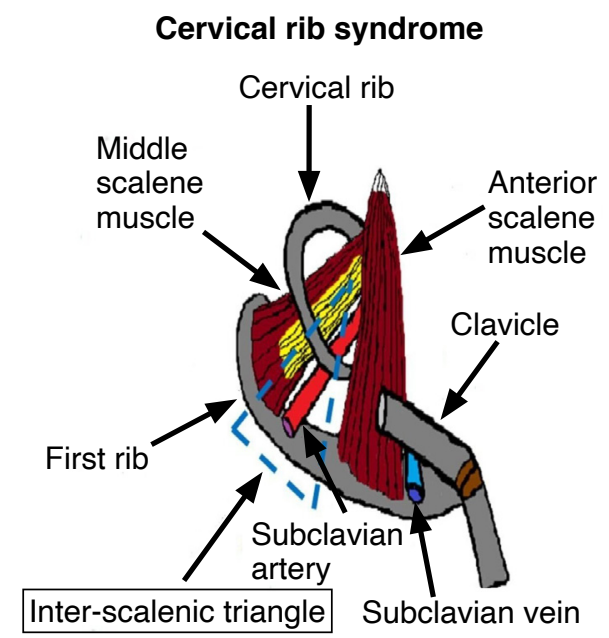

A

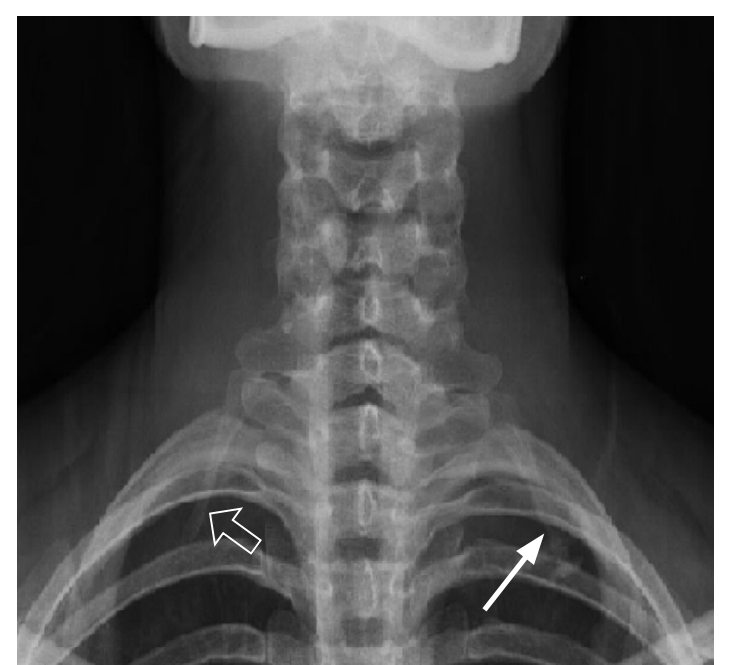

C

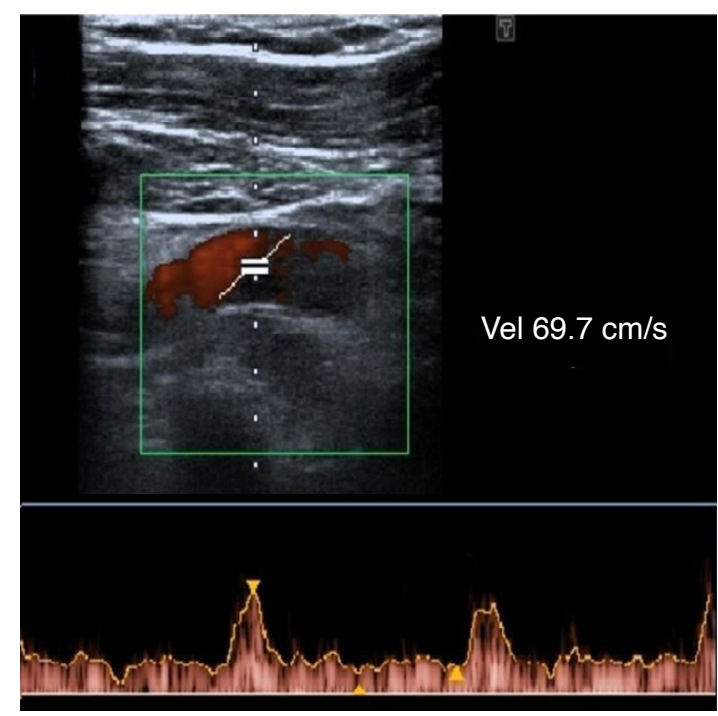

E

\section{Hypertrophic scalene syndrome}

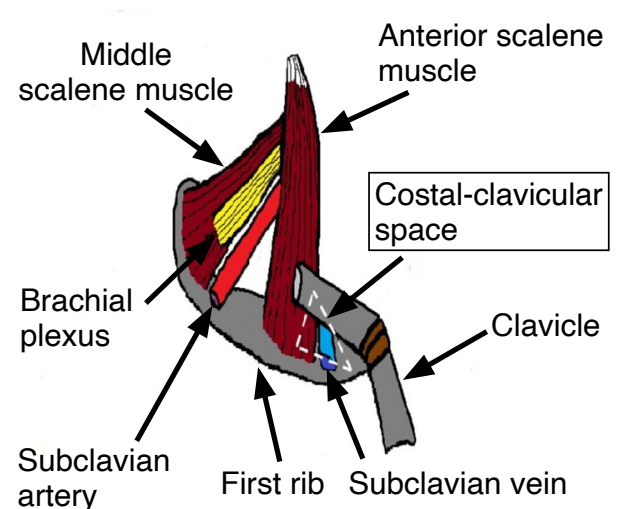

B

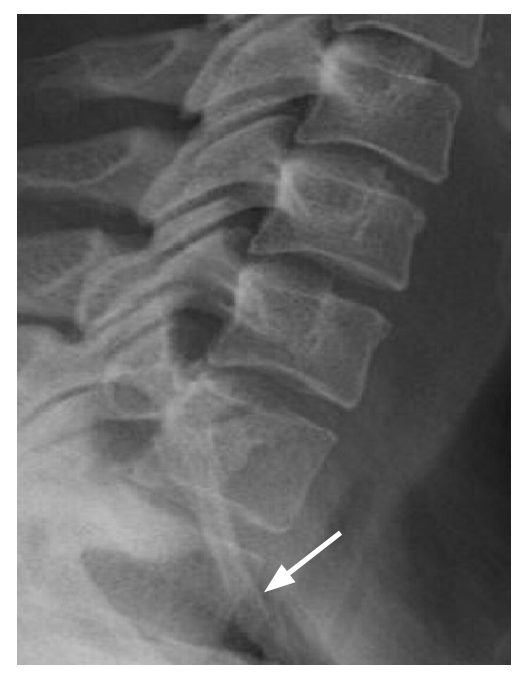

D
Fig. 2. Summary schematic graphical presentation and some representative X-ray and Doppler ultrasonography (DU) images of thoracic outlet syndrome.

A. Diagram summarizes the anatomical structures of the shoulder involved in cervical rib syndrome. The interscalenic triangle is bounded inferiorly by the clavicle, laterally by the middle scalene muscle, and medially by the anterior scalene muscle. Compression of the subclavian artery and/or brachial plexus by cervical rib may occur in this space. B. Diagram summarizes the anatomical structures of the shoulder involved in scalene muscle hypertrophy. The costalclavicular space is delimited inferiorly by the first rib, superiorly by the clavicle, and medially by the anterior scalene muscle. In this space, subclavian vein compression occurs by the hypertrophic anterior scalene muscle. C. Standard $X$-ray of the cervical spine shows a cervical rib to the right (open arrow) and to the left (arrow). D. An X-ray lateral spine view shows a cervical rib (arrow). E, F. Duplex DU: peak systolic velocity (PSV) measurement of the subclavian artery in a healthy patient shows no significant variation between the lowered arm position (E) and the raised arm position (F).

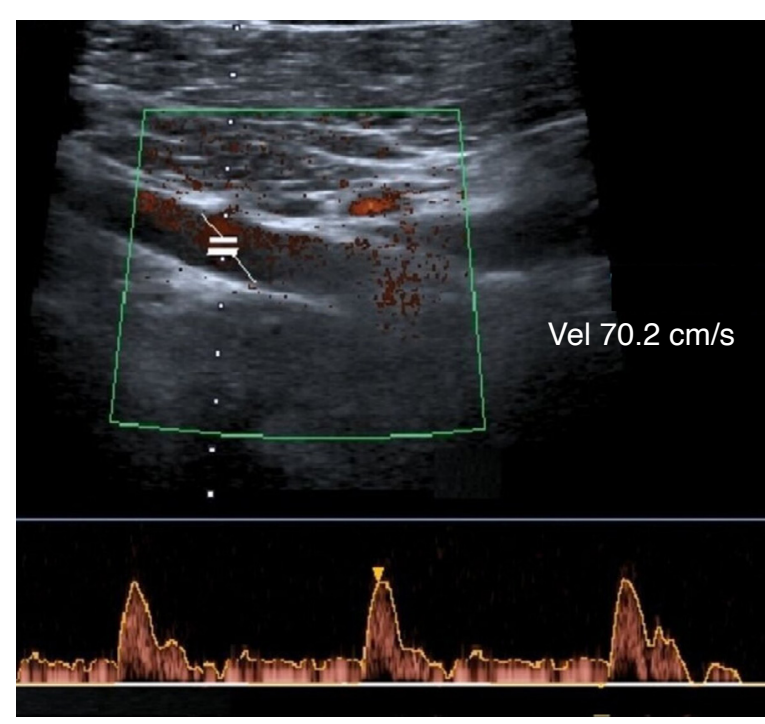

F 


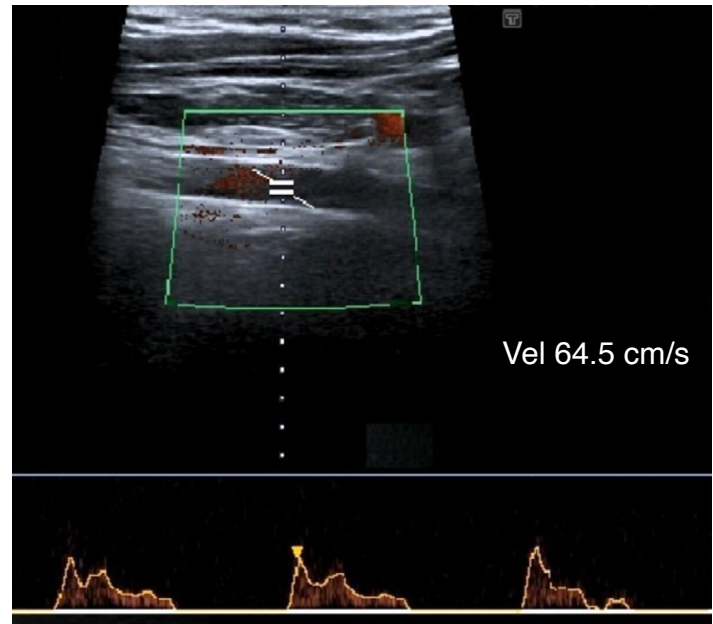

G

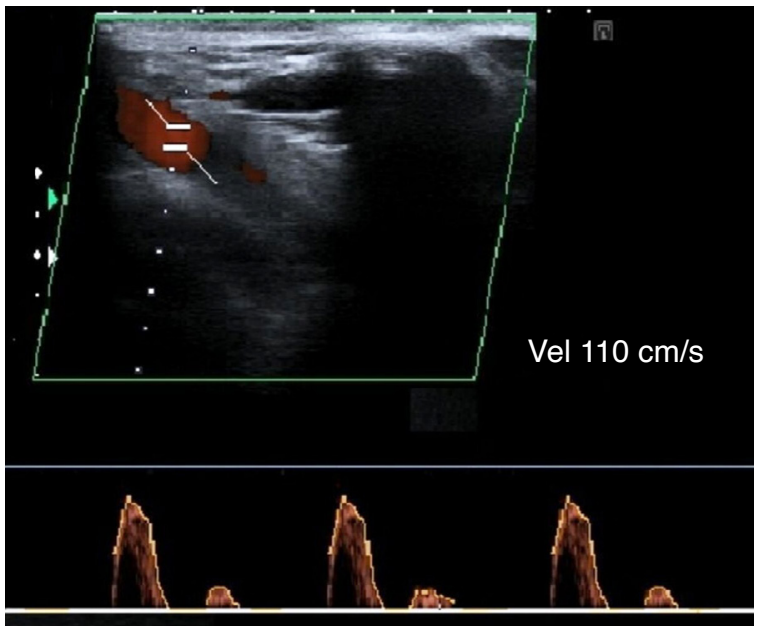

$\mathrm{H}$

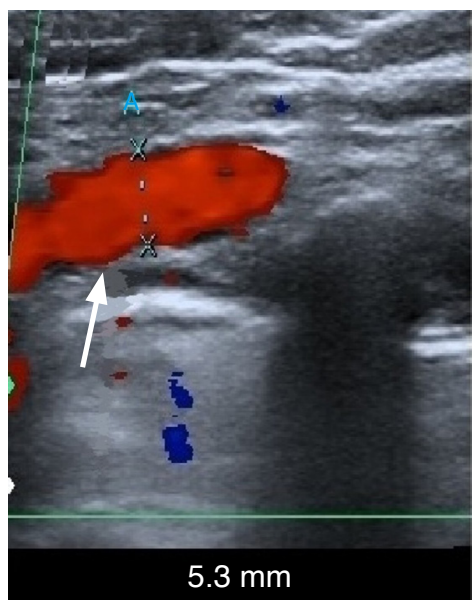

।

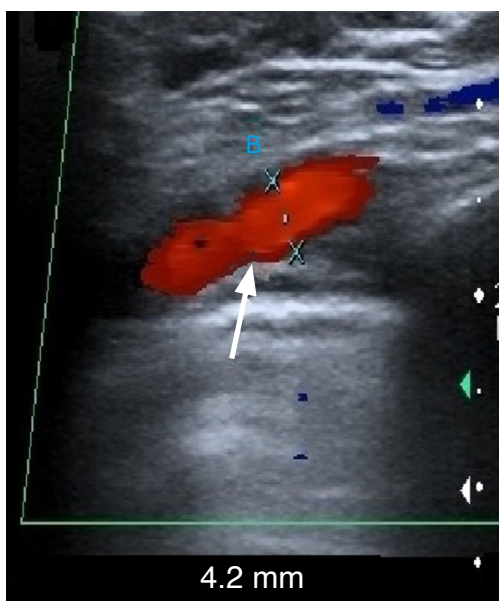

J

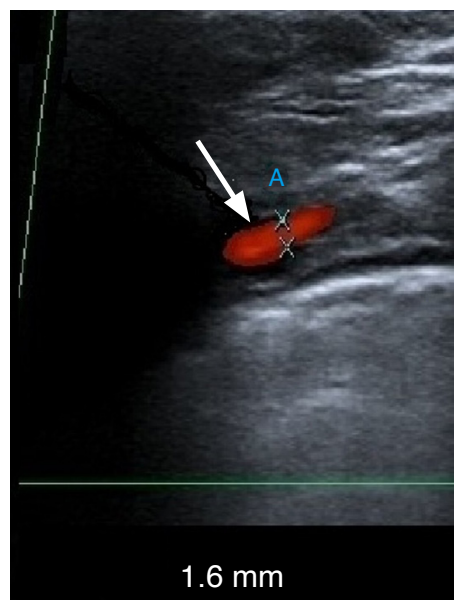

K

Fig. 2. G-K. In patients with cervical rib syndrome, PSV significantly increases when passing from the lowered arms position (G) to that with raised arms $(H)$, due to subclavian artery compression caused by a cervical rib. Color DU of the subclavian artery in the inter-scalenic triangle with the arms lowered $(\mathrm{I})$, arms at $90^{\circ}(\mathrm{J})$, and arms raised $(\mathrm{K})$ shows a progressive reduction in caliber (arrows) due to the hypertrophic anterior scalene muscle.

LRV stenosis, which can cause venous hypertension, renal failure, microhematuria, left flank pain, and secondary left varicocele and LRV thrombosis. If WS is also present, the aforementioned symptoms can be associated with duodenal subocclusion signs: nausea, belching, postprandial pain, and biliary vomiting. Asymptomatic compression of the LRV is called the nutcracker phenomenon [30].

\section{Instrumental Diagnosis}

DU is the first-line exam for the diagnosis of ANCS because it enables a highly precise calculation of the aorto-mesenteric angle and aorto-mesenteric distance, highlights congestion of LRV flow and secondary varicocele, and allows the clinician to estimate the degree of LRV stenosis with FR measurements. CT can also show the vascular alterations typical of ANCS (Fig. 3D-F) and PNCS (Fig. $3 G, H$ ). In patients with a combination of ANCS and symptomatic duodenal stenosis (WS), DU may show signs of ANCS (Fig. 4A, B) but not duodenal compression, so the ultrasound study must necessarily be integrated with $\mathrm{CT}$, which will show the signs of aorto-mesenteric angle reduction but also signs of duodenal compression, such as prestenotic and gastric duodenal dilatation (Fig. 4C), as well as the so-called hook sign typical of ANCS due to aorto-mesenteric angle reduction (Fig. $4 \mathrm{D}$ ). Ultrasonography and $\mathrm{CT}$ in some patients may underestimate the strictures; in these cases, IVUS and venography with measurement of the renocaval pressure gradient allow doubts to be resolved and the best therapeutic approach to be chosen [31]. 
Healthy patient

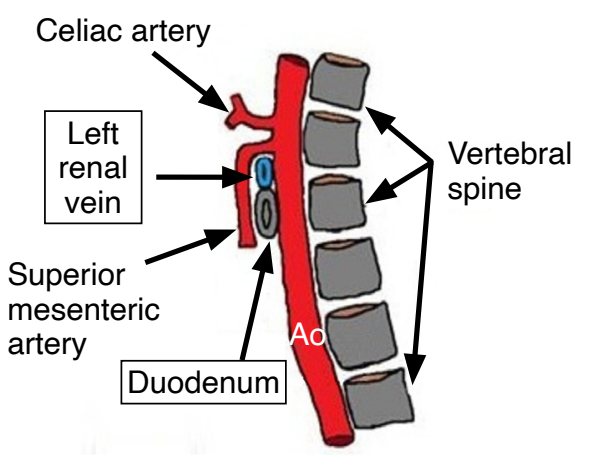

A

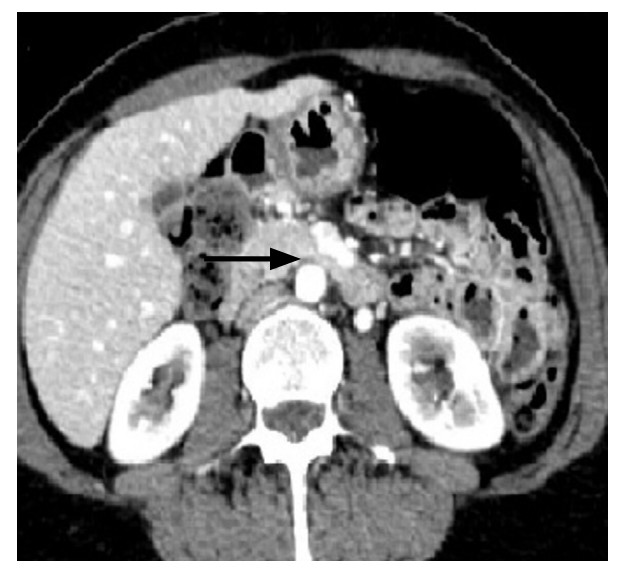

D
Anterior nutcracker syndrome

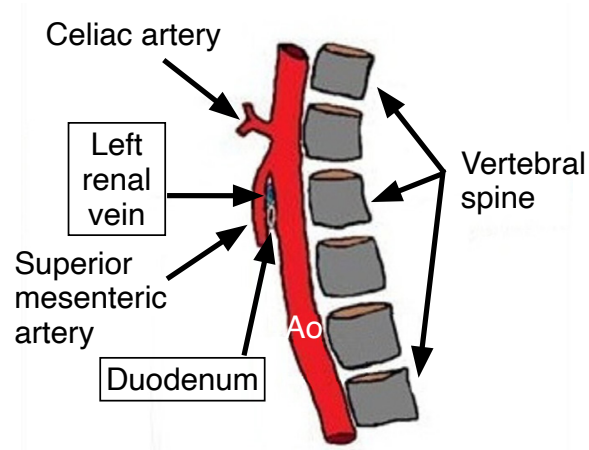

B

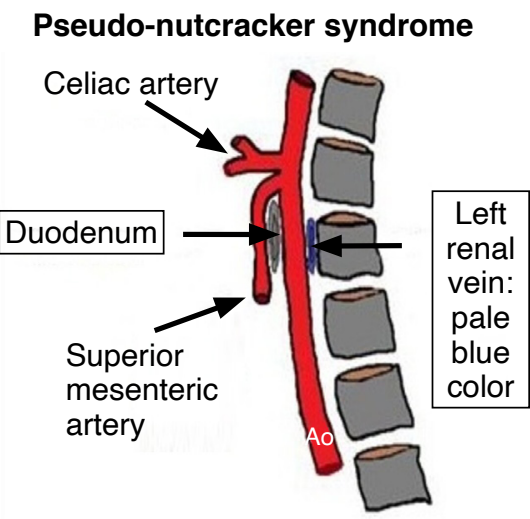

C

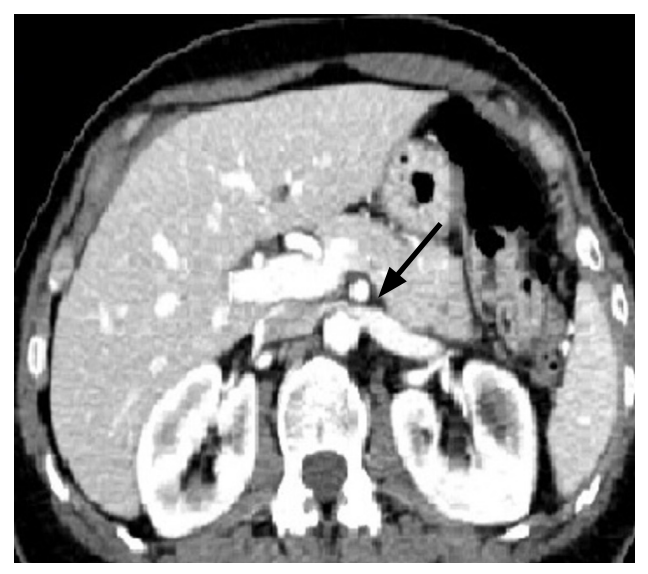

E

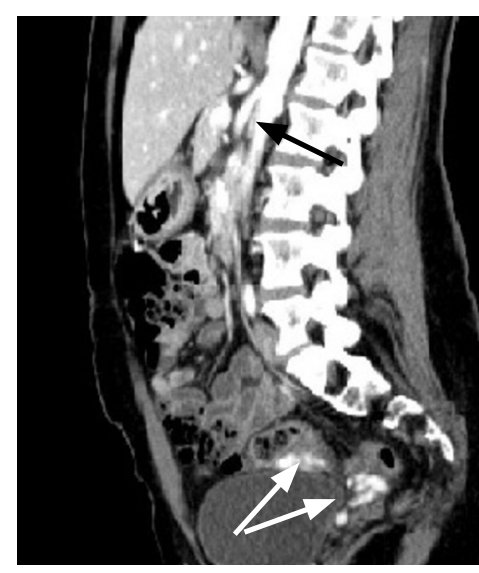

F

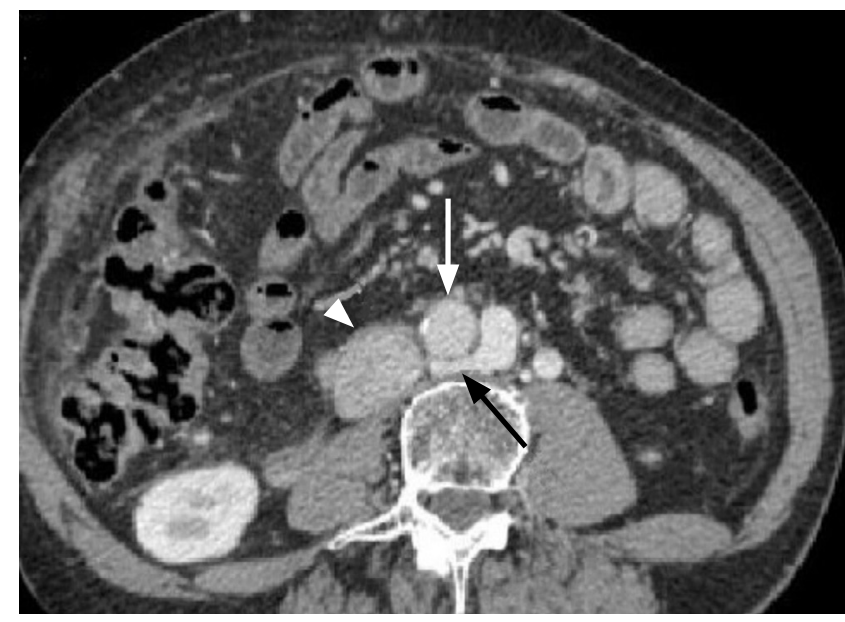

G

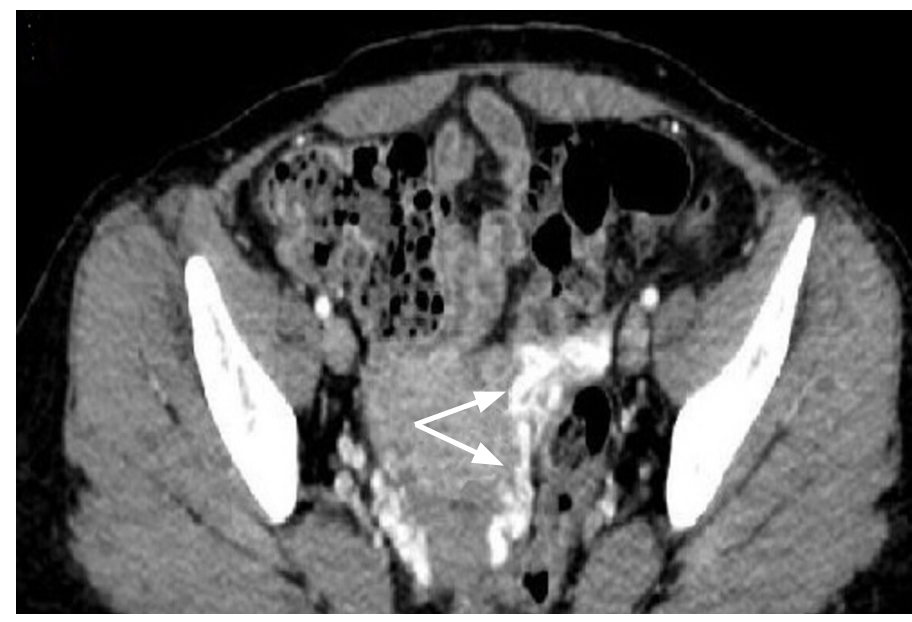

$\mathrm{H}$

Fig. 3. Summary schematic graphical presentation and some representative computed tomography (CT) images of nutcracker syndrome.

A. Summary diagram in the sagittal plane describes the relationships between the superior mesenteric artery, abdominal aorta, left renal vein and duodenum; a healthy patient with a normal aorto-mesenteric angle $\left(>22^{\circ}\right)$. B. In anterior nutcracker syndrome (ANCS), an aorto-mesenteric angle less than $22^{\circ}$ causes left renal vein compression. C. In pseudo-nutcracker syndrome (PNCS), the retroaortic left renal vein is compressed by the abdominal aorta, which pushes it towards the spine. Ao, abdominal aorta. D. ANCS, CT view in the axial plane shows duodenum compression in the aorto-mesenteric space (arrow). E. In this section, compression of the left renal vein (arrow) is evident. F. CT view in the sagittal plane shows the characteristic beak sign (black arrow) due to the superior mesenteric artery originating from aorta with acute angle. White arrows indicate varicocele. G. PNCS: In this CT view in the axial plane, left retroaortic renal vein compression (black arrow) is highlighted, which appears compressed by the aorta (arrow) against spine. Arrowhead indicates inferior cava vein. H. This section shows varicosity of the gonadal plexus veins (arrows) due to flow congestion in the left retroaortic renal vein. 


\section{Treatment}

Patients with ANCS should initially consume a high-calorie diet to restore perivascular adipose tissue and a normal aorto-mesenteric angle [32]. If the diet fails, endovascular stenting may be the

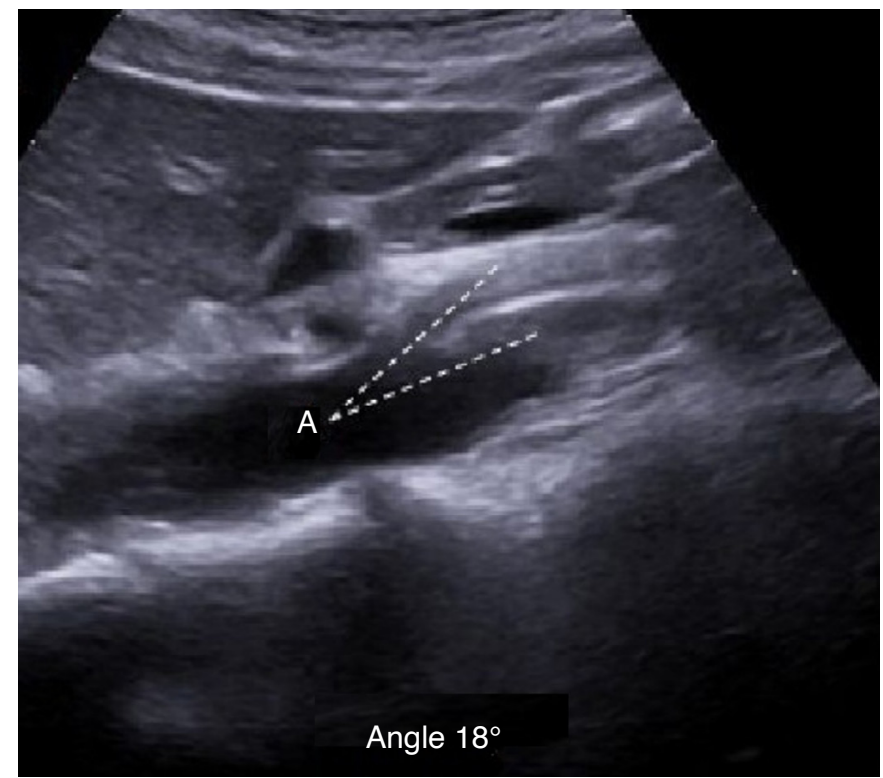

A

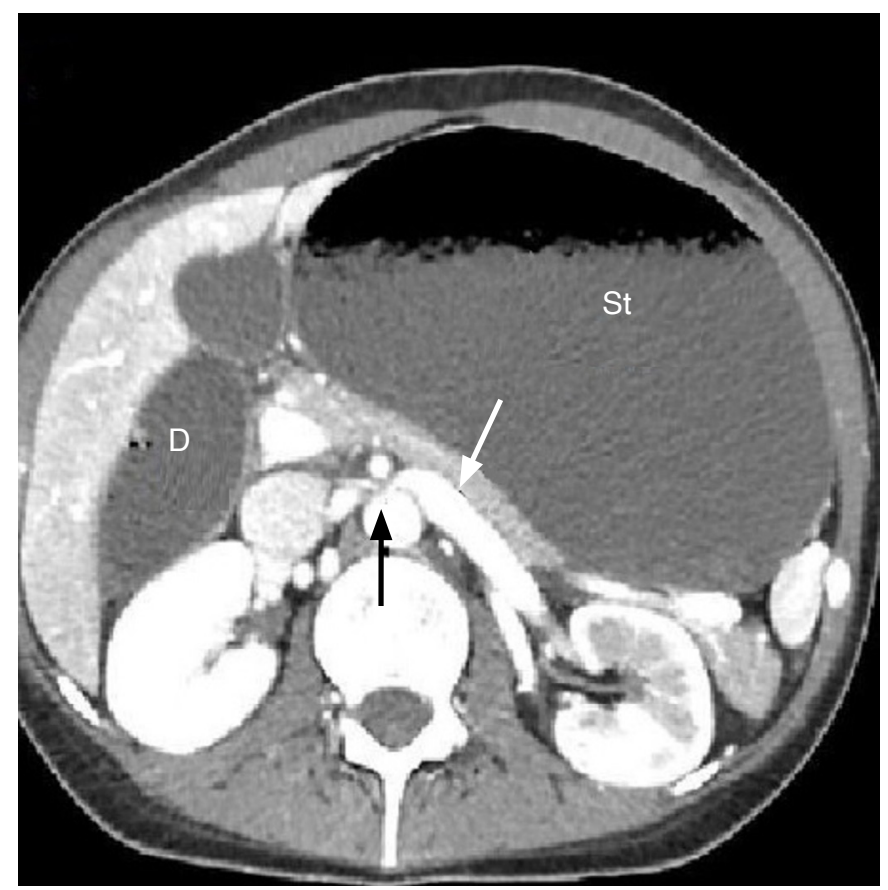

C

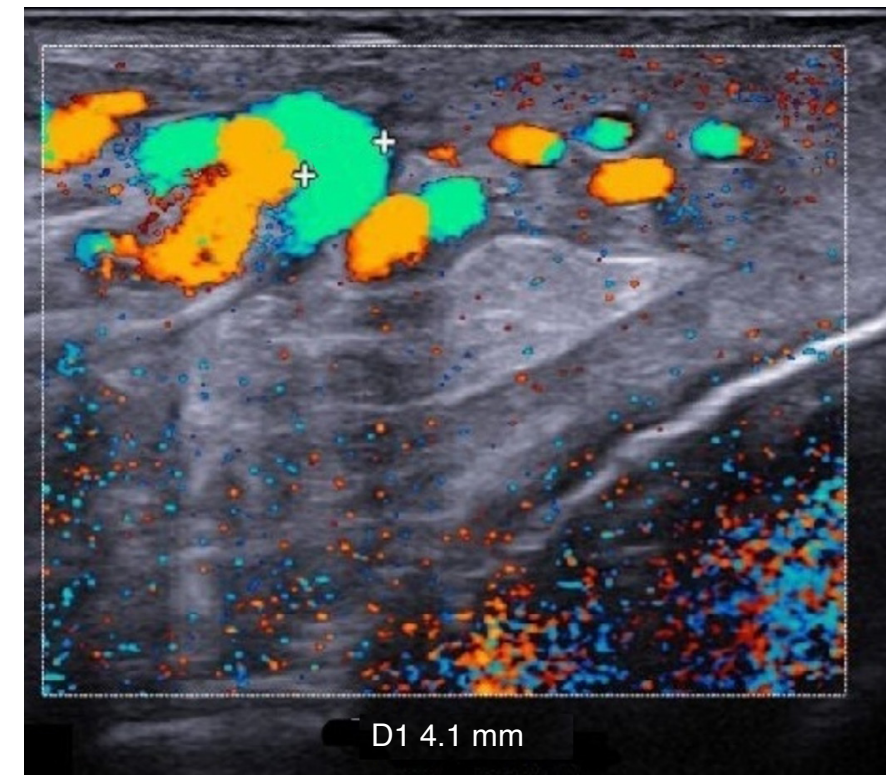

B

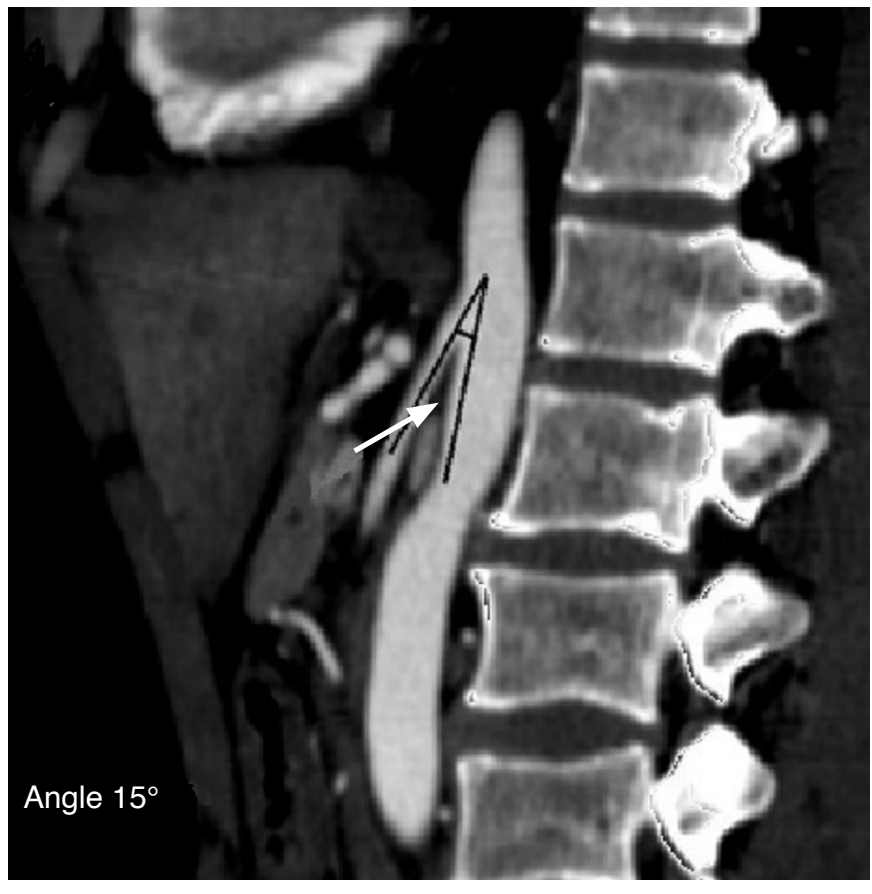

D

Fig. 4. Patient with the combination of nutcracker syndrome and superior mesenteric artery syndrome.

A. B-mode ultrasonography (US) of the abdominal aorta shows a reduction of the aorto-mesenteric angle $\left(18^{\circ}\right)$. B. Color Doppler US of the pampiniform plexus shows left varicocele $(4.1 \mathrm{~mm}$, vein diameter). C. In this computed tomography (CT) view, in the axial plan, left renal vein (arrow) compression is highlighted in the aorto-mesenteric space (black arrow) and in the same view. It is possible to observe stomach (St) and duodenum (D) overdistension caused by duodenal stenosis. D. This CT view in the sagittal plane shows the characteristic beak sign of anterior nutcracker syndrome with aorto-mesenteric angle reduction (arrow). 
solution [33], as placing a stent in the LRV can widen the aortomesenteric angle (Video clip 3) and restore normal vascular flow. However, the stent is not free from the complications of migration and obstruction; therefore, it must be subjected to periodic ultrasound or angiographic checks (Fig. 5A-D). The surgical treatment of SMA syndrome is more invasive, but allows excellent results and consists of resection of the first duodenal loop and retro- vascular duodenum, with subsequent packaging of the anastomosis between the duodenum and second duodenal loop, which are brought anteriorly [34]. The surgical treatment of NCS is usually renal vein transposition, although gonadal vein transposition is another possible technique.

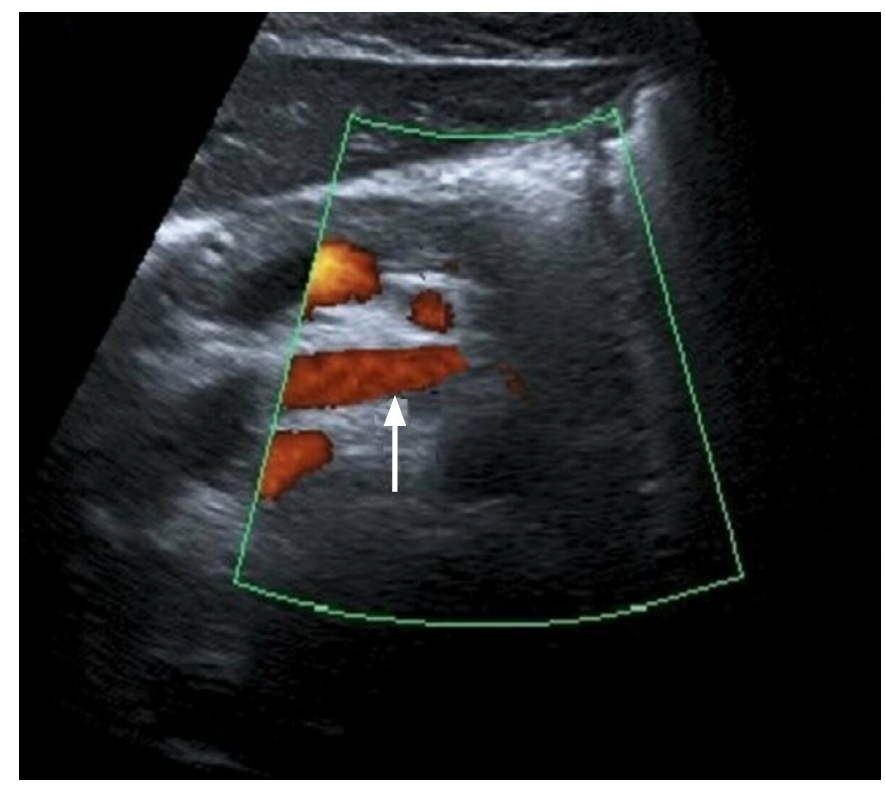

A

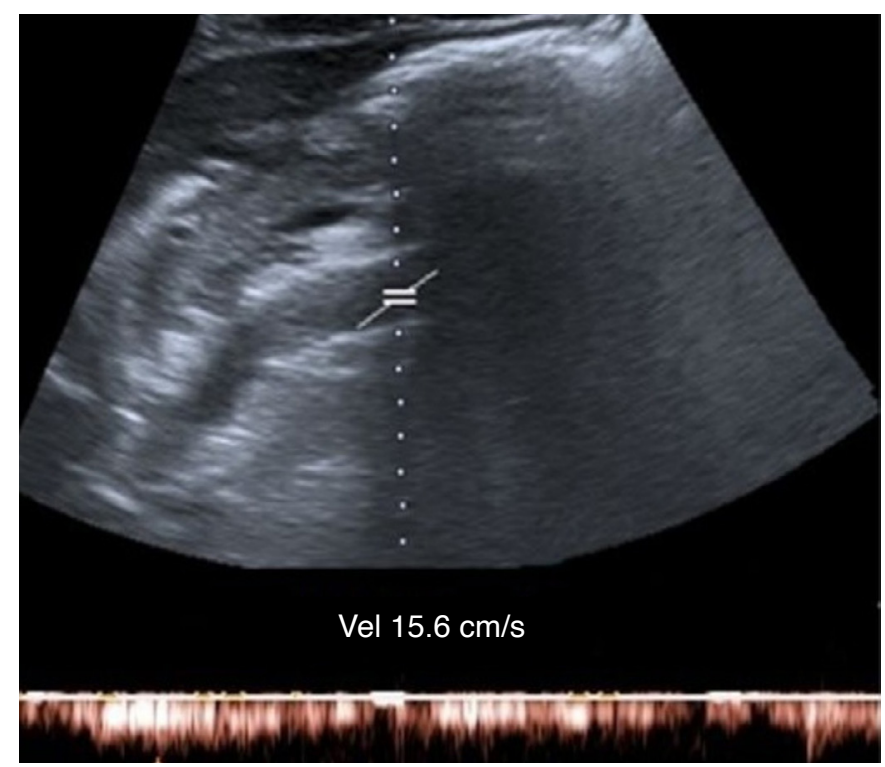

C

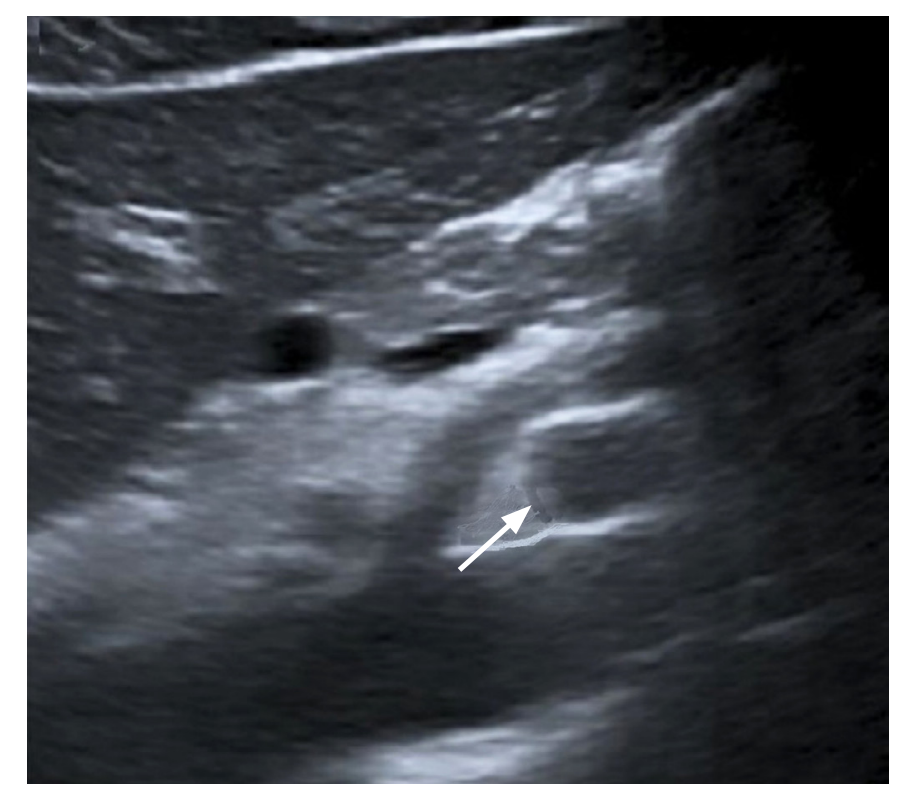

B

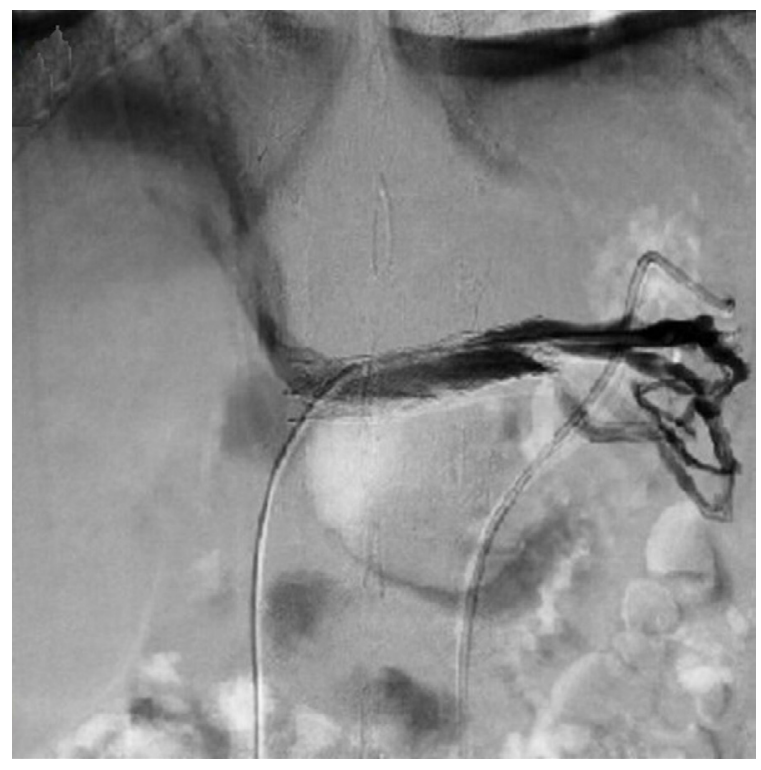

D

Fig. 5. Patient with nutcracker syndrome: monitoring of left renal vein patency after endovascular stenting.

A. Power Doppler ultrasonography (US) can be used for stent patency monitoring due to the ability to sample very slow flows. Left renal vein (arrow) after stenting. B. B-mode US shows left renal vein stent (arrow) which induces an increase in the aorto-mesenteric angle. C. Duplex Doppler US highlights stent patency. D. Selective angiography makes it possible to verify stent patency. 


\section{May-Thurner Syndrome}

\section{Introduction}

MTS was first described in 1957 by May and Thurner [35]. It is a vascular alteration due to left common iliac vein (LCIV) compression, caused in $84 \%$ of cases by the right common iliac artery (RCIA), which pushes the LCIV against the spine, causing circulation congestion with chronic thrombosis (Fig. 6A, B, Video clip 4). Stenosis can result from a hardening of the LCIV wall in contact with the RCIA caused by chronic pulsations of the arterial vessel, which induces an elastin and collagen accumulation that causes venous congestion. In rare cases, stenosis is caused by the left common iliac artery [36] and even more rarely by both common iliac arteries [37]. MTS can be congenital or acquired; acquired MTS can often result from spine osteophytes, abdominal or pelvic masses, or aneurysms [38], which reduce the passage between the spine and the iliac arteries.

\section{Clinical Implications}

The symptoms of MTS are those typical of deep venous congestion, including claudication, limb swelling, pain, thrombophlebitis, and thrombosis. Its risk factors are the same as those of deep vein thrombosis of lower limbs, such as pregnancy, prolonged immobilization, and coagulation abnormalities; in these cases, and

\section{May-Thurner syndrome}

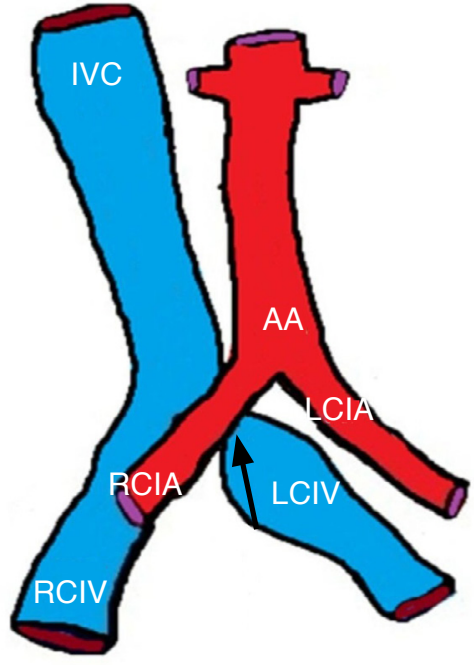

A

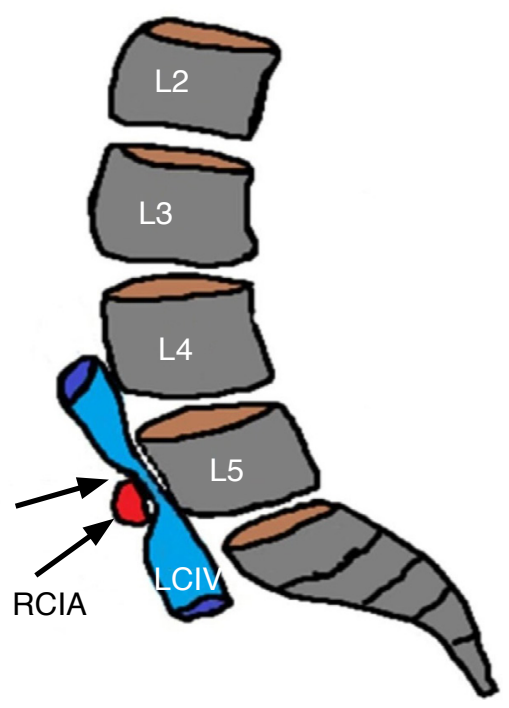

B
Fig. 6. Summary schematic graphical presentation and some representative computed tomography (CT) images of May-Thurner syndrome.

A. This schematic graphic in the coronal plane view shows right common iliac artery ( $R C \mid A)$-induced compression of the left common iliac vein (LCIV), compressing it against the spine at the point indicated by the black arrow. B. This diagram in the sagittal plane shows LCIV compression, which usually occurs against the fifth lumbar vertebra (arrows). C. In this CT view in the axial plane, it is possible to observe LCIV (arrow) compression caused by the RCIA (open arrow), which compresses it against the fifth lumbar vertebra (L5). Arrowhead indicates left common iliac artery (LCIA). D. CT view in the sagittal plane shows RCIA (open arrow) compressing the LCIV (arrow) against the fifth lumbar vertebra (L5). IVC, inferior vena cava; RCIV, right common iliac vein; $\mathrm{AA}$, abdominal aorta.

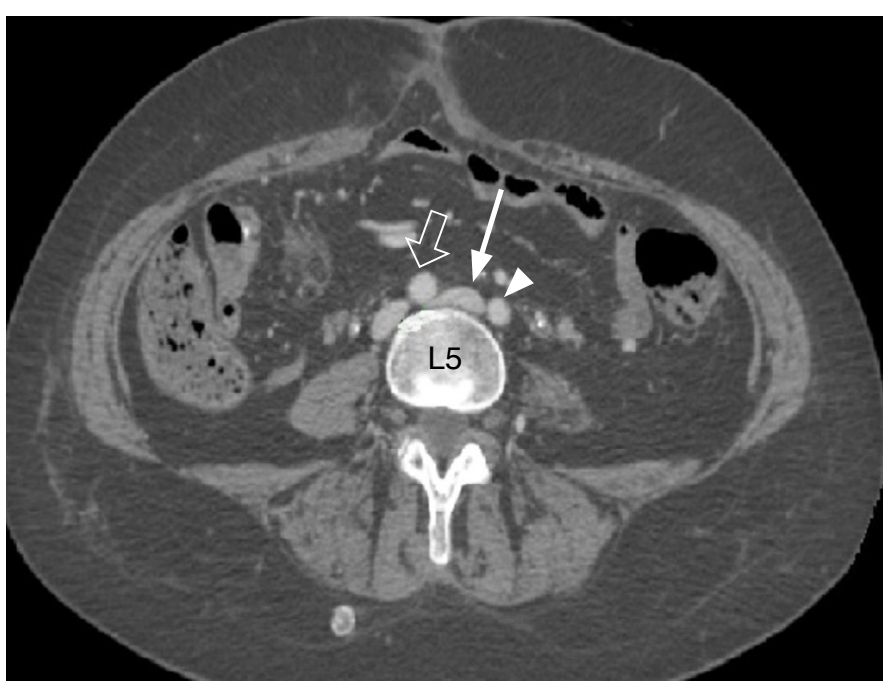

C

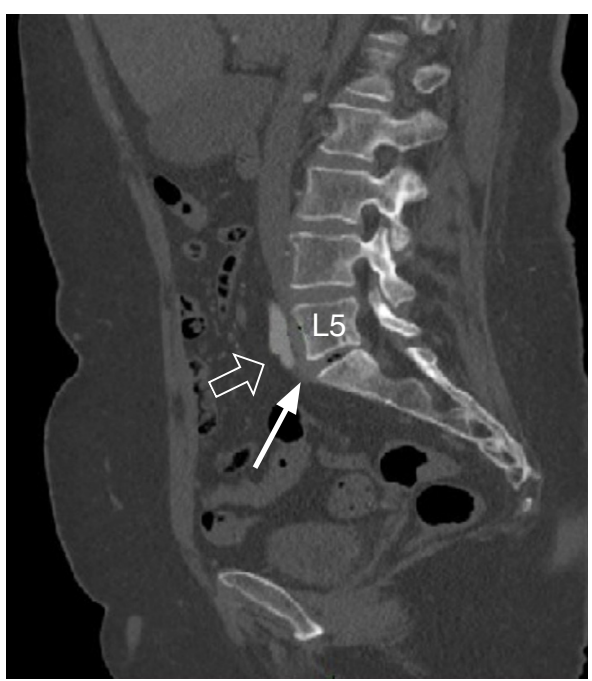

D 
especially in individuals affected by chronic symptoms of the left lower limb, it is necessary to exclude MTS since, if present, the lack of diagnosis could expose patients to serious complications such as thrombosis and pulmonary embolism [39].

\section{Instrumental Diagnosis}

CT can easily highlight LCIV compressions, which can be clearly seen both in axial and sagittal planes (Fig. 6C, D). It also makes it possible to exclude other causes of compression and complications, such as pulmonary and cerebral embolism. DU is the first-line examination for diagnosing MTS, and B-mode US enables the clinician to highlight the LCIV stenosis and indirect signs such as prestenotic and poststenotic dilatation (Fig. 7A, B). In these patients, DU can also be used for FR measurement in order to correctly

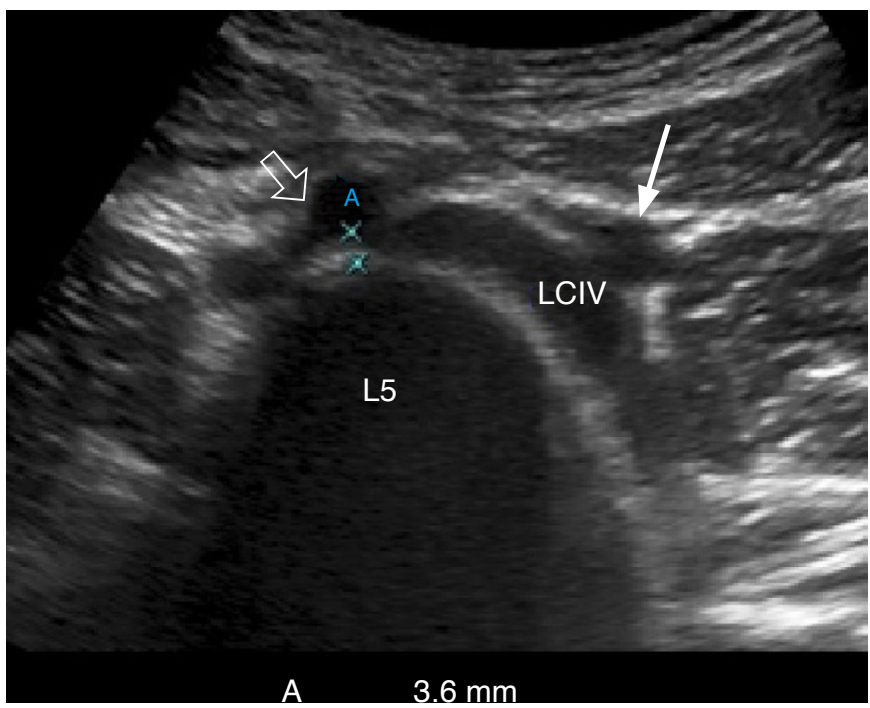

A
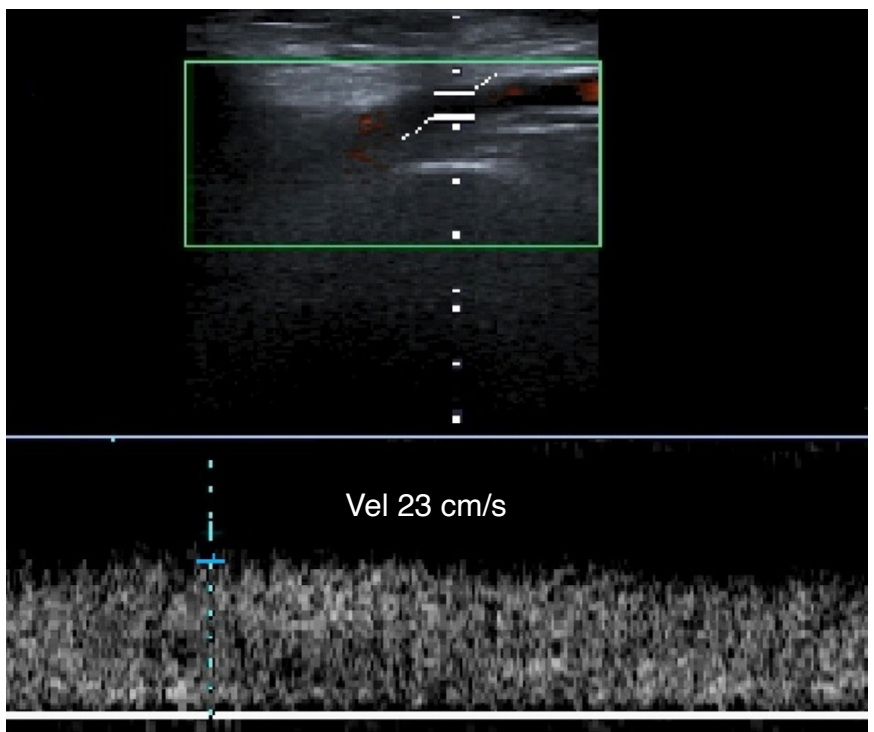

C

Fig. 7. Characteristic ultrasound findings of May-Thurner syndrome.

A. In this B-mode ultrasound (US) transversal scan, the space between the right common iliac artery (RCIA; open arrow) and the fifth lumbar vertebra (L5) appears very narrow (3.6 mm in diameter). The left common iliac artery (LCIA) is shown with a arrow. B. This scan shows prestenotic (A) and poststenotic (B) dilatation of the left common iliac vein (LCIV), showing the fifth lumbar vertebra (L5), RCIA (open arrow), and LCIA (arrow). C, D. Duplex Doppler US of the LCIV shows a significant increase in the peak systolic velocity in the poststenotic tract $(23 \mathrm{~cm} / \mathrm{s})(C) \mathrm{compared}$ to the prestenotic tract $(7 \mathrm{~cm} / \mathrm{s})$ (D).

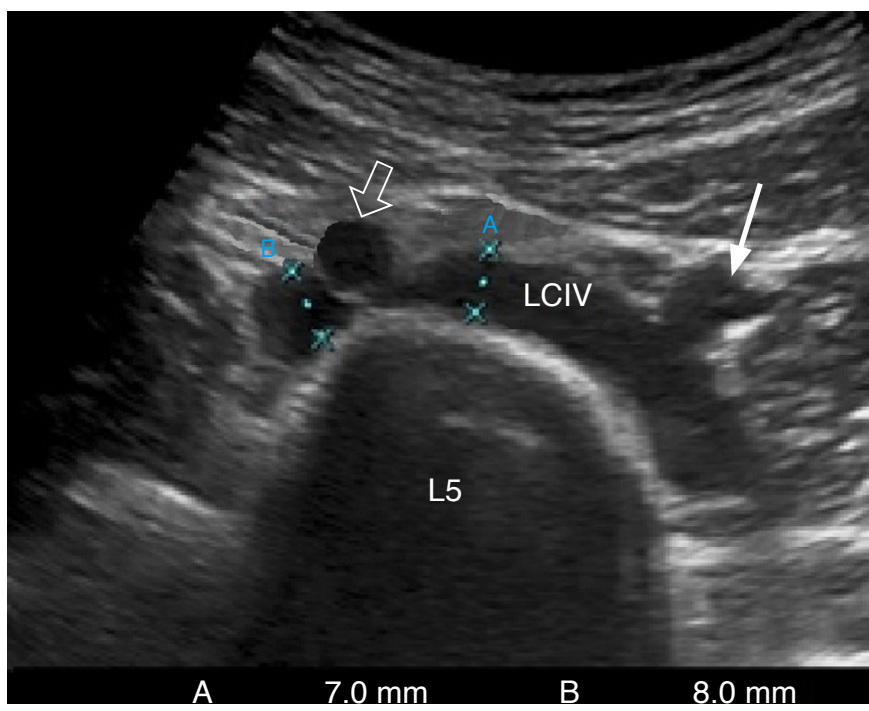

B
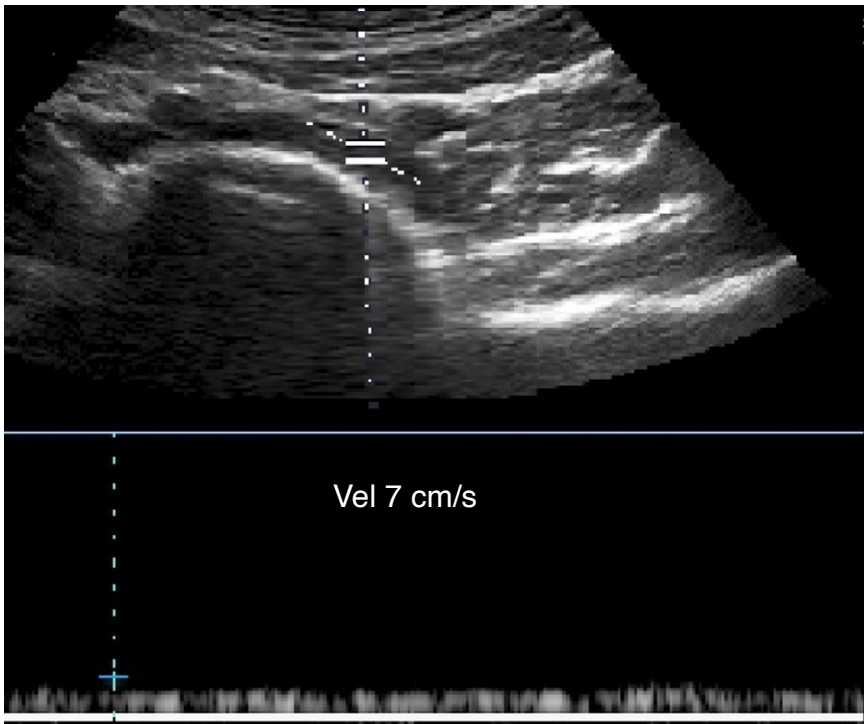

D 
plan the therapeutic treatment (Fig. 7C, D). MRI can show LCIV compression and can be used as an alternative to $\mathrm{CT}$ in patients with renal insufficiency or an allergy to radiological contrast media [40]. Although venography underestimates the severity of LCIV stenosis, it can be useful for the study of collateral vessels. IVUS is a very valid alternative, especially for selecting patients to undergo endovascular stenting of the LCIV [41].

\section{Treatment}

In asymptomatic patients with mild LCIV compression $(<50 \%)$, there is no indication for treatment; while in those with compression greater than $50 \%$, prophylaxis with long-term anticoagulant drugs is indicated. In patients with severe stenosis or thrombosis of the LCIV, endovascular thrombolysis can be decisive and should be followed by long-term prophylaxis with anticoagulant drugs. According to the authors, symptomatic patients with extensive thrombosis should undergo thrombolysis with or without filter placement in the inferior vena cava, followed by an endovascular stent; in these patients, endovascular treatment is $91 \%$ successful [42]. Sixty percent of cases of deep vein thrombosis affects the left lower limb, whereas MTS has only been reported in $2 \%-3 \%$ of cases; however, this low incidence could be attributed to a high frequency of false negatives, probably due to clinicians' poor knowledge of this syndrome and the low specificity of symptoms.

\section{Dunbar Syndrome}

\section{Introduction}

Median arcuate ligament (MAL) syndrome, also known as DS [43], is caused by compression of the celiac artery (CA) and/or neural ganglion by the MAL of the diaphragm, which in these patients has a lower insertion than normal. Therefore, during exhalation, the lifting of the diaphragm causes compression of the CA (Fig. $8 A)$. DS is very rare, with an incidence of 2 in 100,000 patients. CA compression is often asymptomatic because of numerous shunts with the SMA [44].

\section{Clinical Presentation}

There is a syndromic triad typical of DS: epigastric pain, postprandial epigastric murmur, and weight loss. Epigastric pain is accentuated with forced expirations and after meals; this symptom, typical of the disease, does not yet have clear mechanisms. In fact, there is still no consensus regarding its origin, as some authors argue that it is caused by celiac plexus compression and others by CA ischemia [45]. The syndrome can be congenital or acquired, usually after surgery [46]. It has a higher incidence in women. In symptomatic patients, epigastric pain simulates cardiac ischemia and increases after meals, which is why patients lose weight chronically in an attempt to limit its onset.

\section{Instrumental Diagnosis}

DU is the first-line examination for DS diagnosis, and it enables the clinician to highlight CA compression that appears or is accentuated in expiratory apnea (Fig. 8B, Video clip 5). Color DU can highlight chromatic artifacts caused by turbulent flow in the narrowing (Fig. $8 C$, Video clip 6), and duplex DU can measure the PSV increase in the expiratory phase, which can reach values higher than 200 $\mathrm{cm} / \mathrm{s}$ (Fig. 8D, E). As in venous vascular compression, the degree of stenosis can be measured using the FR that is obtained from the ratio of the PSV between the CA and aorta; in this regard, the authors use cutoff values of PSV $>200 \mathrm{~cm} / \mathrm{s}$ or a CA/aorta PSV ratio greater than 3:1 as thresholds beyond which symptoms occur. CT and MRI can highlight stenosis of the CA if care is taken to perform the examinations in inspiratory and expiratory apnea; however, the disease is often not discovered because routine examinations are performed only in inspiratory apnea. CT also serves to rule out any other causes of CA compression (Fig. 8F). In sagittal-plane images, CT shows the characteristic hook sign due to proximal CA stenosis and poststenotic dilatation (Fig. 8G). Selective angiography is a reference test for diagnosis, but it is more invasive than other imaging techniques. IVUS is particularly useful for identifying patients to undergo surgical correction because, according to the authors, other methods tend to underestimate stenosis [47].

\section{Treatment}

The treatment of choice is surgery, with release of open MAL and celiac ganglionectomy by laparoscopic [48] or robotic techniques [49]. The procedure depends on the disease stage; in less severe cases, only surgical decompression is performed, while cases with periarterial fibrosis need to be supplemented by arteriolysis. Surgical treatment should be performed only after all other causes of abdominal pain have been excluded. In cases of relapse (7\%), endovascular stenting is used [50]. The most reliable treatment in the long term appears to be a combination of surgery and vascular stenting [51].

\section{Popliteal Entrapment Syndrome}

\section{Introduction}

PES is generally caused by extrinsic compression of the popliteal artery, popliteal vein, and tibial nerve (singly or in combination) by musculoskeletal structures. It is usually caused by an abnormal course of the medial head or third head of the gastrocnemius muscle, or by a gastrocnemius muscle abnormality. Other less 


\section{Dunbar syndrome}

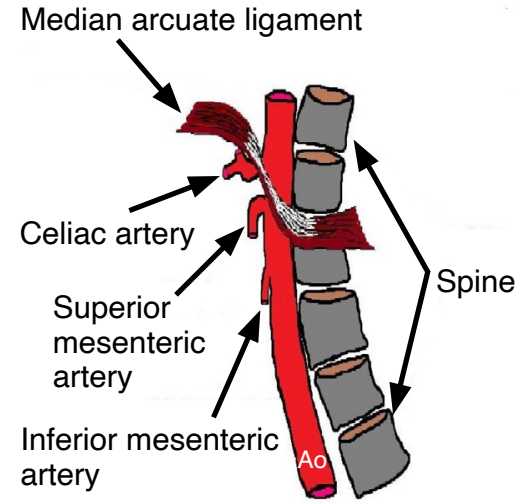

A

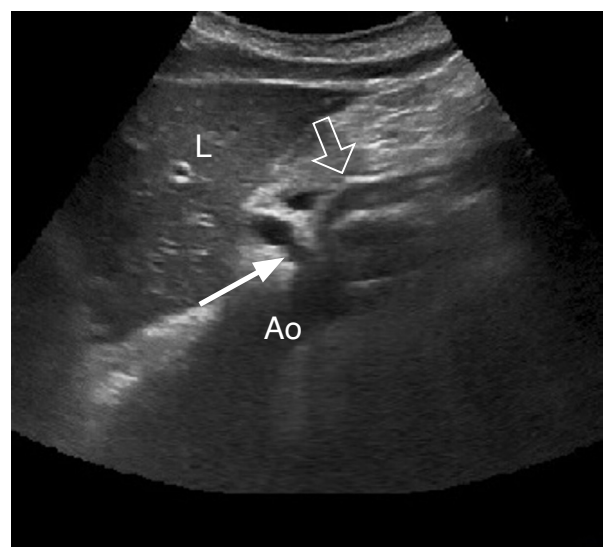

B

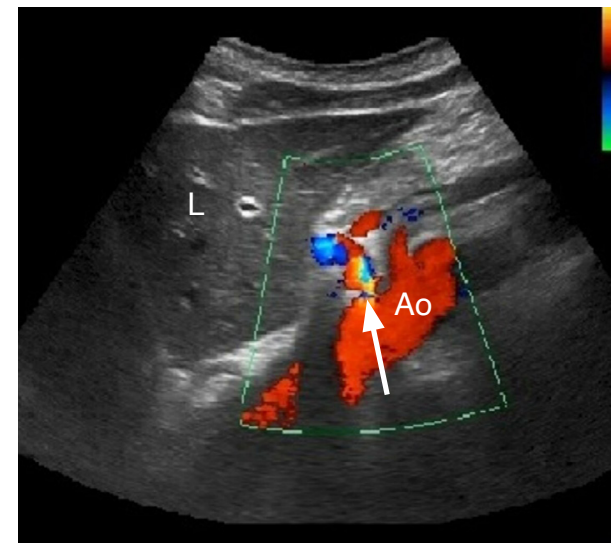

C

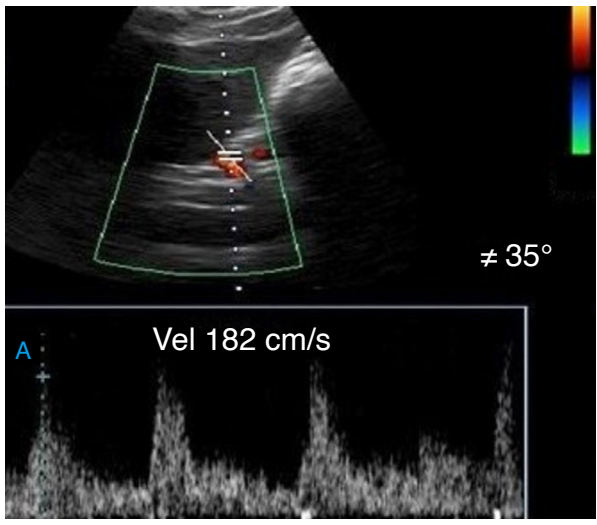

D

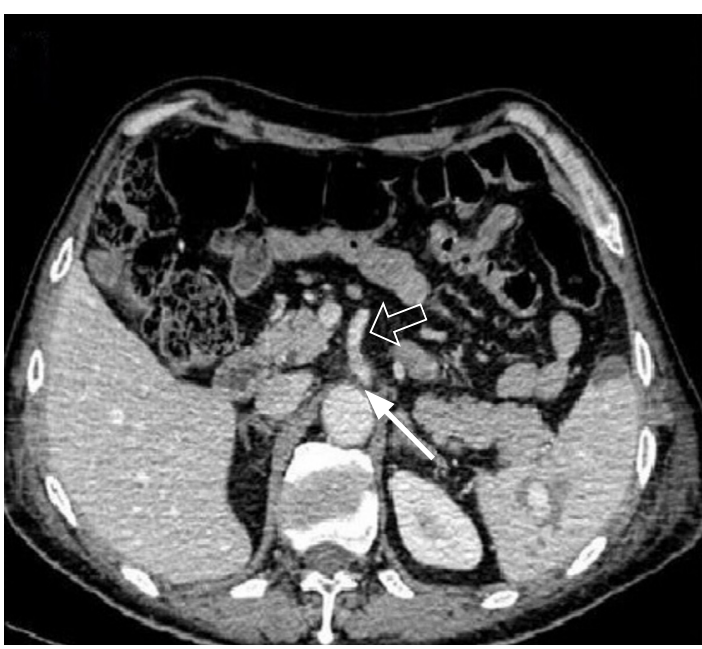

$\mathrm{F}$

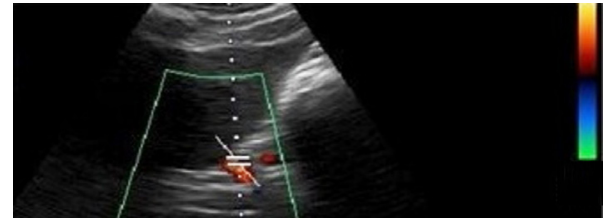

$\neq 35^{\circ}$
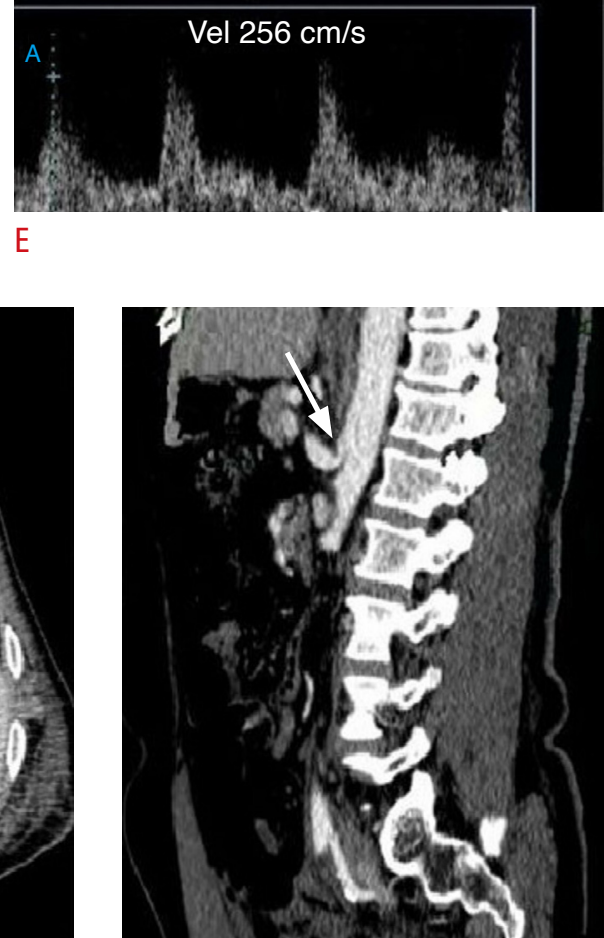

G
Fig. 8. Summary schematic graphical presentation and some representative ultrasound (US) and computed tomography (CT) images of Dunbar syndrome (DS).

A. Diagram in the sagittal plane: a more caudal course of the median arcuate ligament causes celiac artery (CA) stenosis in the expiratory apnea phase. Ao, abdominal aorta. B. B-mode US longitudinal scan in inspiratory apnea shows a regular CA diameter (arrow), the superior mesenteric artery (open arrow), the Ao, and the liver (L). C. Color Doppler US Iongitudinal scan in expiratory apnea shows severe CA stenosis (arrow) with poststenotic dilatation and chromatic aliasing due to turbulent flow. D. Duplex Doppler US of the CA in inspiratory apnea shows a slight peak systolic velocity (PSV) increase $(182 \mathrm{~cm} / \mathrm{s})$. E. Duplex Doppler US of the CA in expiratory apnea shows a substantial increase in the PSV $(256 \mathrm{~cm} / \mathrm{s})$ due to severe stenosis at the CA origin. F. CT view in the axial plane shows CA stenosis at the origin (arrow). The CA is shown by a open arrow. G. CT view in the sagittal plane shows the characteristic hook sign of DS with CA stenosis (arrow) and poststenotic dilatation. common causes reported in the literature are thickening of perivenous fascia, hypertrophic fibrous fascia, hypertrophy of the popliteal muscle, aponeurosis of the soleus muscle, an aneurysmal popliteal artery, and popliteal cyst (Baker's cyst) [52]. In accordance with the classification of Wehlan as modified by Rich, PES can be divided into six types on the basis of the anatomic abnormality 
causing entrapment:

Type 1: The medial head of the gastrocnemius muscle is normal, but the popliteal artery has an aberrant medial course around the head.

Type 2: The medial head of the gastrocnemius muscle has an abnormal insertion laterally to the popliteal artery.

Type 3: An abnormal slip of the medial head of the gastrocnemius muscle surrounds the popliteal artery.

Type 4: The popliteal artery is located deeply within the popliteal fossa and is entrapped by a fibrous band or by the popliteus muscle.

Type 5: The popliteal vein is entrapped by any of the above types $(\mathrm{I}-\mathrm{IV})$.

Type 6: Functional type: Popliteal artery and vein entrapment is caused by muscle hypertrophy.

Type 3 is most common and occurs in 30\% of the cases [53]. Popliteal artery compression can be isolated or can coexist with venous entrapment (Fig. 9A-C) and with tibial nerve entrapment, causing vascular and neurogenic symptoms. This phenomenon occurs in $10 \%-15 \%$ of the population [54]. The prevalence of PES is unknown, although it occurs predominantly in healthy and young individuals. Obesity represents one of the risk factors [55]. In 22\%$67 \%$ of patients, popliteal artery syndrome is bilateral [56]. Vascular compression is of pathological significance only when it leads to hemodynamic alterations; otherwise, it can be considered as a "physiological phenomenon" [57].

\section{Clinical Implications}

The clinical presentation includes a wide range of signs and symptoms that occur during exercise.

The symptoms of onset are claudication and exercise-induced leg pain, which are reported by $90 \%$ of patients. The most common symptoms are varicose veins, pain and tightness in the calf, lower leg paresthesia, cramping, blanching and cold feet, edema below the knee, and leg pain that becomes worse with walking [58]. In an advanced state, such as in patients with chronic venous insufficiency, symptoms include heaviness and swelling, pallor, ulcers, edema below the knee, and deep vein thrombosis. For this reason, patients with venous insufficiency with unknown etiopathogenesis should have popliteal compression ruled out as a possible cause [59]. The main complication related to deep vein thrombosis is pulmonary embolism, which is why it must be considered a very dangerous vascular disease.

\section{Instrumental Diagnosis}

DU is the first-line examination for evaluating the femoralpopliteal axis and anatomical anomalies, such as popliteal vessel compression, popliteal artery stenosis, an increase or decrease in peak systolic activity with dynamic compression, acute or chronic thrombosis, post-phlebitic venous insufficiency, and musculoskeletal pathology (Baker's cyst) (Fig. 9D, E) [60]. To identify popliteal artery entrapment syndrome, provocative maneuvers (active plantar flexion and then with the knee flexed at $15^{\circ}$ ) are performed, and the peak flow and peak decrease are measured [61]. Eighty-eight percent of asymptomatic patients may present with popliteal artery occlusion during stress maneuvers [62]. Furthermore, DU shows caliber variation of the vein during plantar flexion to quantify the stenosis degree and reflux in the small saphenous vein in dynamic phases. The venous FR also allows clinicians to estimate the stenosis degree. CT and MRI can give more information on the anatomical abnormalities that can cause compression; in particular, MRI provides a very accurate anatomical study of fibrous bands and abnormal muscle insertions. If other imaging methods fail, the definitive diagnosis is made with ascending venography, but this is an invasive method that should be used only in selected cases. IVUS is highly sensitive and can be used in dynamic phases; in fact, it can highlight dynamic occlusion of the popliteal artery when combined with foot dorsiflexion or plantar flexion maneuvers [63].

\section{Treatment}

Conservative, endovascular, and surgical treatment options can be used. The choice of management depends on the symptoms and stenosis severity. Compression stockings are used in asymptomatic patients or in patients with mild symptoms, catheter-mediated thrombolysis is recommended in acute arterial thrombosis, and long-term anticoagulant treatment is recommended in patients with hemodynamically significant stenosis (>70\%) and in deep vein thrombosis. Endovascular stenting can be used in all patients with hemodynamically significant stenosis. The definitive treatment is surgical and consists of decompression of popliteal vascular structures by fasciotomy with or without muscle-tendon section, and in some cases with vascular reconstruction.

\section{Conclusion}

Undiagnosed vascular compression syndromes can have potentially serious and sometimes fatal sequelae for patients. For this reason, thorough knowledge of the clinical manifestations and characteristic instrumental signs is essential to limit false negatives. The diagnosis may be difficult due to clinicians' lack of knowledge and the rarity of these conditions. The discovery of mild asymptomatic venous or arterial compression should be investigated by measuring the FR because if the stenosis is close to $50 \%$, it should be checked periodically and, in our opinion, long-term anticoagulant drug prophylaxis could be indicated to prevent thrombosis. DU is a noninvasive and non-risky method that is low-cost, reproducible, and 


\section{Popliteal entrapment syndrome}

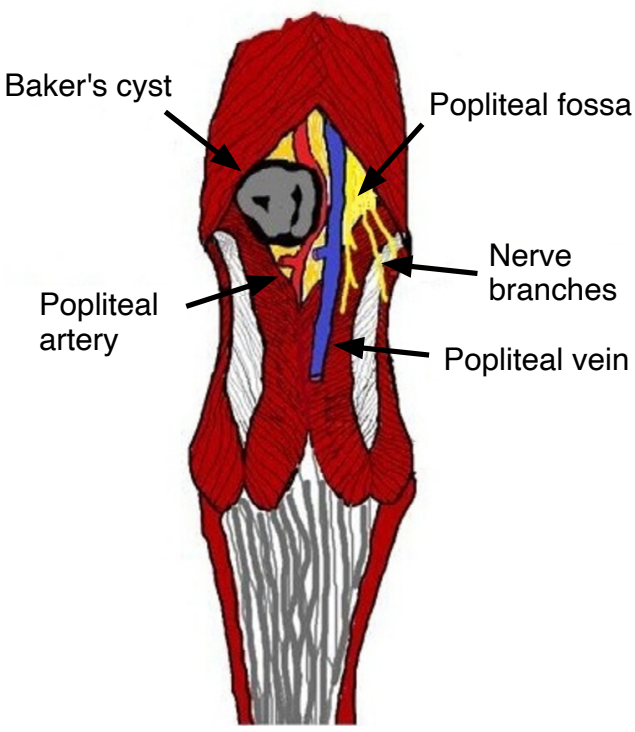

A

Fig. 9. Summary schematic graphical presentation and some representative computed tomography (CT) images of popliteal entrapment syndrome.

A. Diagram in the coronal plane with the popliteal fossa and a Baker's cyst that compresses and diverts the popliteal artery is shown. B. CT view in the coronal plane shows that the popliteal artery (black arrow) is compressed and deflected laterally by the Baker's cyst (arrow). C. CT view in the sagittal plane shows that the popliteal artery (black arrow) is compressed and deflected by the Baker's cyst (arrow). D. CT view in the coronal plane shows that the popliteal vein (arrows) is compressed by the lateral gastrocnemius muscle (arrowsheads). E. CT view in the axial plane shows the Baker's cyst (arrow) that causes compression and thrombosis of popliteal vein (arrowheads). Open arrow indicates popliteal artery.

repeatable; its wider use in chronic or at-risk subjects would allow earlier and more effective treatments.

ORCID: Renato Farina: https://orcid.org/0000-0002-1132-7813, Pietro Valerio Foti: https:// orcid.org/0000-0002-0918-0103; Isabella Pennisi: https://orcid.org/0000-0002-66633105; Tiziana Vasile: https://orcid.org/0000-0003-2032-3491; Mariangela Clemenza: https://orcid.org/0000-0003-3493-0962; Giuliana La Rosa: https://orcid.org/0000-00020686-3048; Luca Crimi: https://orcid.org/0000-0003-0106-9141; Marco Catalano: https:// orcid.org/0000-0003-1920-3943; Francesco Vacirca: https://orcid.org/0000-0002-4627-

\section{2; Antonio Basile: https://orcid.org/0000-0002-3480-7086}

\section{Author Contributions}

Conceptualization: Farina R. Data acquisition: Farina R, Foti PV, Pennisi I, Vasile T, Clemenza M, La Rosa G, Crimi L, Catalano M, Vacirca F, Basile A. Data analysis or interpretation: Farina R, Foti PV, Pennisi I, Vasile T, Clemenza M, La Rosa G, Crimi L, Catalano $M$, Vacirca F, Basile A. Drafting of the manuscript: Farina R, Foti 
PV, Pennisi I, Vasile T, Clemenza M, La Rosa G, Crimi L, Catalano $M$, Vacirca F, Basile A. Critical revision of the manuscript: Farina $R$, Basile A. Approval of the final version of the manuscript: all authors.

\section{Conflict of Interest}

No potential conflict of interest relevant to this article was reported.

\section{Supplementary Material}

Video clip 1. Eagle syndrome. B-mode ultrasound longitudinal scan shows dilation and venous congestion in the prestenotic tract of the left internal jugular vein (https://doi.org/10.14366/usg.21233.v001).

Video clip 2. Anterior nutcracker syndrome. B-mode ultrasound longitudinal scan of the abdominal aorta shows severe reduction of the aorto-mesenteric angle (https://doi.org/10.14366/usg.21233.v002).

Video clip 3. Anterior nutcracker syndrome. Selective angiography: examination after endovascular stenting in the left renal vein (https:// doi.org/10.14366/usg.21233.v003).

Video clip 4. May-Thurner syndrome. Color Doppler ultrasound scan shows compression of the left common iliac vein by the right common iliac artery, causing thrombosis of the tract upstream of stenosis (https://doi.org/10.14366/usg.21233.v004).

Video clip 5. Dunbar syndrome. B-mode ultrasound scan shows stenosis at the celiac artery origin detectable in the expiratory phase (https://doi.org/10.14366/usg.21233.v005).

Video clip 6. Dunbar syndrome. Color Doppler ultrasound scan performed in the expiratory phase shows severe stenosis at the celiac artery origin, which causes poststenotic flow turbulence with chromatic aliasing (https://doi.org/10.14366/usg.21233.v006).

\section{References}

1. Gozzo C, Farina R, Foti PV, lannace FA, Conti A, Pennisi I, et al. Posterior nutcracker syndrome: a case report. J Med Case Rep 2021;15:42.

2. Acampora C, Di Serafino $M$, lacobellis F, Trovato $P$, Barbuto $\mathrm{L}$, Sangiuliano $\mathrm{N}$, et al. Insight into Dunbar syndrome: colorDoppler ultrasound findings and literature review. J Ultrasound 2021;24:317-321.

3. Kpodonu J, Ramaiah VG, Diethrich EB. Intravascular ultrasound imaging as applied to the aorta: a new tool for the cardiovascular surgeon. Ann Thorac Surg 2008;86:1391-1398.
4. Sigdel B, Karn M, Sah K. Bilateral elongated styloid processes: eagle syndrome. Lancet 2021;397:1387.

5. Zamboni P, Scerrati A, Menegatti E, Galeotti R, Lapparelli M, Traina L, et al. The eagle jugular syndrome. BMC Neurol 2019;19:333.

6. Bai C, Wang Z, Guan J, Jin K, Ding Y, Ji X, et al. Clinical characteristics and neuroimaging findings in eagle syndrome induced internal jugular vein stenosis. Ann Transl Med 2020;8:97.

7. Mooney J, Lepard J, Akbari SH, Johnston JM. Styloidogenic jugular venous compression syndrome: a case report and review of the literature. Childs Nerv Syst 2020;36:3135-3139.

8. Zhao X, Cavallo C, Hlubek RJ, Mooney MA, Belykh E, Gandhi $S$, et al. Styloidogenic jugular venous compression syndrome: clinical features and case series. Oper Neurosurg (Hagerstown) 2019;17:554-561.

9. Aydin E, Quliyev H, Cinar C, Bozkaya H, Oran I. Eagle syndrome presenting with neurological symptoms. Turk Neurosurg 2018;28:219-225.

10. Ikenouchi H, Takagi M, Nishimura A, Yamaguchi E, Koge J, Saito K, et al. Bilateral carotid artery dissection due to Eagle syndrome in a patient with vascular Ehlers-Danlos syndrome: a case report. BMC Neurol 2020;20:285.

11. Han MK, Kim DW, Yang JY. Non surgical treatment of Eagle's syndrome: a case report. Korean J Pain 2013;26:169-172.

12. Hooker JD, Joyner DA, Farley EP, Khan M. Carotid stent fracture from stylocarotid syndrome. J Radiol Case Rep 2016;10:1-8.

13. Li M, Gao X, Rajah GB, Liang J, Chen J, Yan F, et al. Styloidectomy and venous stenting for treatment of styloid-induced internal jugular vein stenosis: a case report and literature review. World Neurosurg 2019;130:129-132.

14. Czako L, Simko K, Thurzo A, Galis B, Varga I. The syndrome of elongated styloid process, the Eagle's syndrome: from anatomical, evolutionary and embryological backgrounds to 3D printing and personalized surgery planning: report of five cases. Medicina (Kaunas) 2020;56:458.

15. Ruopsa N, Ristolainen L, Vastamaki M, Vastamaki H. Neurogenic thoracic outlet syndrome with supraclavicular release: long-term outcome without rib resection. Diagnostics (Basel) 2021;11:450.

16. Lahiri R, Chauhan U, Kumar A, Puliyath N. Undiagnosed bilateral complete cervical rib with subclavian artery aneurysm presenting as acute ischaemic limb following high-altitude expedition. BMJ Case Rep 2021;14:e241194.

17. Farina R, Foti PV, lannace FA, Conti A, Ferlito A, Conti A, et al. Thoracic outlet syndrome: a rare case with bilateral cervical ribs and bilateral anterior scalene hypertrophy. J Ultrasound 2021;24:331336.

18. Baltopoulos P, Tsintzos C, Prionas G, Tsironi M. Exercise-induced scalenus syndrome. Am J Sports Med 2008;36:369-374.

19. Hixson KM, Horris HB, McLeod TCV, Bacon CE. The diagnostic accuracy of clinical diagnostic tests for thoracic outlet syndrome. J 
Sport Rehabil 2017;26:459-465.

20. Hardy A, Pouges C, Wavreille G, Behal H, Demondion X, Lefebvre $G$. Thoracic outlet syndrome: diagnostic accuracy of MRI. Orthop Traumatol Surg Res 2019;105:1563-1569.

21. Kim TI, Sarac TP, Orion KC. Intravascular ultrasound in venous thoracic outlet syndrome. Ann Vasc Surg 2019;54:118-122.

22. Buonocore M, Manstretta C, Mazzucchi G, Casale R. The clinical evaluation of conservative treatment in patients with the thoracic outlet syndrome. G Ital Med Lav Ergon 1998;20:249-254.

23. Pesser N, Goeteyn J, van der Sanden L, Houterman S, van Alfen $N$, van Sambeek $M$, et al. Feasibility and outcomes of a multidisciplinary care pathway for neurogenic thoracic outlet syndrome: a prospective observational cohort study. Eur J Vasc Endovasc Surg 2021;61:1017-1024.

24. Ikeda N, Nakamura M, Hara H, Takagi T, Sugi K. Combined endovascular and open surgical approach for the management of subclavian artery occlusion due to thoracic outlet syndrome. J Card Surg 2011;26:309-312.

25. Farina R, Gozzo C, Foti PV, Conti A, Vasile T, Pennisi I, et al. A man with the rare simultaneous combination of three abdominal vascular compression syndromes: median arcuate ligament syndrome, superior mesenteric artery syndrome, and nutcracker syndrome. Radiol Case Rep 2021;16:1264-1270.

26. Butros SR, Liu R, Oliveira GR, Ganguli S, Kalva S. Venous compression syndromes: clinical features, imaging findings and management. Br J Radiol 2013;86:20130284.

27. Eldefrawy A, Arianayagam M, Kanagarajah P, Acosta K, Manoharan $M$. Anomalies of the inferior vena cava and renal veins and implications for renal surgery. Cent European J Urol 2011;64:4-8.

28. Requena-Lopez AA, Mata-Samperio BK, Cuadra-Reyes LA, CasillasVargas R. Wilkie's syndrome as a cause of bowel obstruction in adults: a case report. Cir Cir 2020;88:185-188.

29. Farina R, lannace FA, Foti PV, Conti A, Ini C, Libra F, et al. A case of nutcracker syndrome combined with wilkie syndrome with unusual clinical presentation. Am J Case Rep 2020;21:e922715.

30. Rassi I, Khabbaz Z, Chelala D, Jebara VA. A new variant of the posterior nutcracker phenomenon. J Vasc Surg 2010;51:1279.

31. Neupane S, Ambulgekar N, Edla S, Torey J, Gottam N, Yamasaki H. Intravascular ultrasound-guided endovascular stenting of renal vein in nutcracker syndrome. Vasc Endovascular Surg 2018;52:355-356.

32. Farina R, Foti PV, Cocuzza G, Costanzo V, Costanzo G, Conti A, et al. Wilkie's syndrome. J Ultrasound 2017;20:339-342.

33. Belczak SQ, Coelho Neto F, de Araujo WJ, Godoy JM. Endovascular treatment of anterior nutcracker syndrome and pelvic varices in a patient with an anterior and a posterior renal vein. BMJ Case Rep 2020;13:e235284.

34. Denchev B, Domuschieva E, Jelev G, Govedarski V, Zahariev T. Surgical treatment of a patient with nutcracker syndrome via transposition of the left renal vein. EJVES Short Rep 2018;41:10-
12.

35. May R, Thurner J. The cause of the predominantly sinistral occurrence of thrombosis of the pelvic veins. Angiology 1957;8:419-427.

36. Al-Nouri 0, Milner R. May-Thurner syndrome. Vasc Dis Manage 2011;8:53-56.

37. Farina R, Foti PV, lannace FA, Conti A, Pennisi I, Coppolino $P$, et al. May-Thurner syndrome with double compression of the iliac vein: lessons based on a case report. Am J Case Rep 2021;22:e928957.

38. Yi JA, Hadley JB, Kuwayama DP. Atypical May-Thurner syndrome caused by endovascular aortic aneurysm repair. J Vasc Surg Cases Innov Tech 2020;6:397-400.

39. Farina R, Foti PV, lannace FA, Fanzone L, Pennisi I, Conti A, et al. May Thurner syndrome: description of a case with unusual clinical onset. J Ultrasound 2022;25:309-313.

40. Hsu YC, Huang YK, Hsu LS, Chen PY, Chen CW. Using non-contrastenhanced magnetic resonance venography for the evaluation of May-Thurner syndrome in patients with renal insufficiency: a case report. Medicine (Baltimore) 2019;98:e18427.

41. Radaideh Q, Patel NM, Shammas NW. Iliac vein compression: epidemiology, diagnosis and treatment. Vasc Health Risk Manag 2019;15:115-122.

42. Mousa AY, AbuRahma AF. May-Thurner syndrome: update and review. Ann Vasc Surg 2013;27:984-995.

43. Farina R, Foti PV, Conti A, lannace FA, Pennisi I, Santonocito $S$, et al. The role of ultrasound in Dunbar syndrome: lessons based on a case report. Am J Case Rep 2020;21:e926778.

44. Heo S, Kim HJ, Kim B, Lee JH, Kim J, Kim JK. Clinical impact of collateral circulation in patients with median arcuate ligament syndrome. Diagn Interv Radiol 2018;24:181-186.

45. Bech FR. Celiac artery compression syndromes. Surg Clin North Am 1997;77:409-424.

46. Takeda FR, Darce GF, Sobrado LF, de Faria LL, Tustumi F, Sallum RA, et al. Post-esophagectomy Symptomatic Dunbar Syndrome: a rare diagnosis of abdominal pain after surgery. Int J Surg Case Rep 2020;68:198-202.

47. de Lara FV, Higgins C, Hernandez-Vila EA. Median arcuate ligament syndrome confirmed with the use of intravascular ultrasound. Tex Heart Inst J 2014;41:57-60.

48. Okada H, Ehara K, Ro H, Yamada M, Saito T, Negami N, et al. Laparoscopic treatment in a patient with median arcuate ligament syndrome identified at the onset of superior mesenteric artery dissection: a case report. Surg Case Rep 2019;5:197.

49. You JS, Cooper M, Nishida S, Matsuda E, Murariu D. Treatment of median arcuate ligament syndrome via traditional and robotic techniques. Hawaii J Med Public Health 2013;72:279-281.

50. Hongsakul K, Rookkapan S, Sungsiri J, Tubtawee T. A severe case of median arcuate ligament syndrome with successful angioplasty and stenting. Case Rep Vasc Med 2012;2012:129870. 
51. Michalik M, Dowgiallo-Wnukiewicz N, Lech P, Majda K, Gutowski P. Hybrid (laparoscopy + stent) treatment of celiac trunk compression syndrome (Dunbar syndrome, median arcuate ligament syndrome (MALS)). Wideochir Inne Tech Maloinwazyjne 2016;11:236-239.

52. Gaweesh AS, Kayed MH, Gaweesh TY, Shata A. Popliteal venous aneurysms and iliac vein compression: a possible association. Phlebology 2014;29:386-389.

53. Levien LJ. Popliteal artery entrapment syndrome. Semin Vasc Surg 2003; 16:223-231.

54. Sinha S, Houghton J, Holt PJ, Thompson MM, Loftus IM, Hinchliffe RJ. Popliteal entrapment syndrome. J Vasc Surg 2012;55:252-262.

55. Dijkstra ML, Khin NY, Thomas SD, Lane RJ. Popliteal vein compression syndrome pathophysiology and correlation with popliteal compartment pressures. J Vasc Surg Venous Lymphat Disord 2013;1:181-186.

56. Zucker EJ, Ganguli S, Ghoshhajra BB, Gupta R, Prabhakar AM. Imaging of venous compression syndromes. Cardiovasc Diagn Ther 2016;6:519-532.

57. White JM, Comerota AJ. Venous compression syndromes. Vasc
Endovascular Surg 2017;51:155-168.

58. Stager A, Clement D. Popliteal artery entrapment syndrome. Sports Med 1999;28:61-70.

59. Misselbeck T, Dangleben D, Celani V. Isolated popliteal vein entrapment by the popliteus muscle: a case report. Vasc Med 2008; 13:37-39.

60. Lane RJ, Cuzzilla ML, Harris RA, Phillips MN. Popliteal vein compression syndrome: obesity, venous disease and the popliteal connection. Phlebology 2009;24:201-207.

61. di Marzo L, Cavallaro A, Sciacca V, Lepidi S, Marmorale A, Tamburelli $A$, et al. Diagnosis of popliteal artery entrapment syndrome: the role of duplex scanning. J Vasc Surg 1991;13:434-438.

62. Hoffmann U, Vetter J, Rainoni L, Leu AJ, Bollinger A. Popliteal artery compression and force of active plantar flexion in young healthy volunteers. J Vasc Surg 1997;26:281-287.

63. Chou HH, Wu IH, Yeh KH, Ko YL, Huang HL. The usefulness of intravascular ultrasound in popliteal artery entrapment syndrome. JACC Cardiovasc Interv 2019;12:2110-2111. 